Article

\title{
Osteointegration of Porous

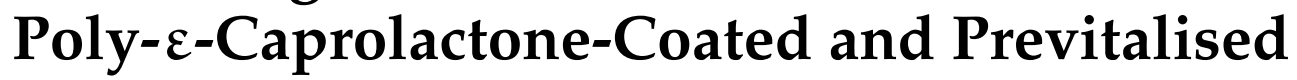 Magnesium Implants in Critically Sized Calvarial Bone Defects in the Mouse Model
}

\author{
Michael Grau ${ }^{1,2,+}$, Christian Seiler ${ }^{3, \dagger}$, Laura Roland ${ }^{1,2}$, Julia Matena ${ }^{1,2}$, Claudia Windhövel ${ }^{1,2}$, \\ Michael Teske ${ }^{4}$, Hugo Murua Escobar ${ }^{1,2}$, Matthias Lüpke ${ }^{3}$ (D) , Hermann Seifert ${ }^{3}$, \\ Nils-Claudius Gellrich ${ }^{5}$, Heinz Haferkamp ${ }^{6}$ and Ingo Nolte ${ }^{1, *}$ \\ 1 Small Animal Clinic, University of Veterinary Medicine Hannover, Foundation, D-30559 Hannover, \\ Germany; michael.grau@tiho-hannover.de (M.G.); laura.roland@yahoo.de (L.R.); \\ julia.matena@gmx.de (J.M.); claudia.windhoevel@tiho-hannover.de (C.W.); \\ hugo.murua.escobar@med.uni-rostock.de (H.M.E.) \\ 2 Division of Medicine Clinic III, Hematology, Oncology and Palliative Medicine, University of Rostock, \\ D-18057 Rostock, Germany \\ 3 Institute for General Radiology and Medical Physics, University of Veterinary Medicine Hannover, \\ Foundation, D-30173 Hannover, Germany; christian.seiler@tiho-hannover.de (C.S.); \\ matthias.luepke@tiho-hannover.de (M.L.); hermann.seifert@tiho-hannover.de (H.S.) \\ 4 Institute for Biomedical Engineering, Rostock University Medical Center, D-18119 Rostock, Germany; \\ michael.teske@uni-rostock.de \\ 5 Clinic for Cranio-Maxillo-Facial Surgery, Hannover Medical School, D-30625 Hannover, Germany; \\ gellrich.nils-claudius@mh-hannover.de \\ 6 Institut fuer Werkstoffkunde, Leibniz Universitaet Hannover, D-30823 Garbsen, Germany; \\ haferkamp@iw.uni-hannover.de \\ * Correspondence: ingo.nolte@tiho-hannover.de; Tel.: +49-511-953-6400; Fax: +49-511-953-6203 \\ + These authors contributed equally to this study.
}

Received: 9 September 2017; Accepted: 18 December 2017; Published: 21 December 2017

\begin{abstract}
Metallic biomaterials are widely used in maxillofacial surgery. While titanium is presumed to be the gold standard, magnesium-based implants are a current topic of interest and investigation due to their biocompatible, osteoconductive and degradable properties. This study investigates the effects of poly- $\varepsilon$-caprolactone-coated and previtalised magnesium implants on osteointegration within murine calvarial bone defects: After setting a $3 \mathrm{~mm} \times 3 \mathrm{~mm}$ defect into the calvaria of $40 \mathrm{BALB} / \mathrm{c}$

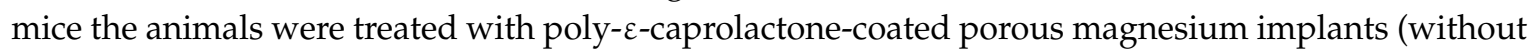
previtalisation or previtalised with either osteoblasts or adipose derived mesenchymal stem cells), porous Ti6Al4V implants or without any implant. To evaluate bone formation and implant degradation, micro-computertomographic scans were performed at day 0, 28, 56 and 84 after surgery. Additionally, histological thin sections were prepared and evaluated histomorphometrically. The outcomes revealed no significant differences within the differently treated groups regarding bone formation and the amount of osteoid. While the implant degradation resulted in implant shifting, both implant geometry and previtalisation appeared to have positive effects on vascularisation. Although adjustments in degradation behaviour and implant fixation are indicated, this study still considers magnesium as a promising alternative to titanium-based implants in maxillofacial surgery in future.
\end{abstract}

Keywords: magnesium; poly-caprolactone; implant; calvarial defect; mouse; in vivo small animal imaging; micro-computed tomography; previtalisation; osteoblast; ADMSC 


\section{Introduction}

In maxillofacial surgery, the treatment of critically sized bone defects whether of neoplastic, traumatic or congenital origin, is still challenging due to insufficient vascularisation and therefore inadequate bone regeneration [1,2]. Originally, the term critically sized defect was defined as the smallest size of a defect that would not heal within the lifetime of the animal [3]. Several studies stated defects with $5 \mathrm{~mm}$ in diameter to be critically sized for calvaria of adult mice [4,5]. Due to convenience issues in animal research a critical defect often alternatively refers to a size that is not able to heal throughout the duration of the experiment [5,6]. Since different studies have shown that defects of $3 \mathrm{~mm}$ in diameter set within the calvaria of mice did not heal within a period of 12 weeks [7-9], the same criteria were chosen for this study both time and dimension wise. For closing critically sized defects, autografts harvested from intact bone are commonly used. However, this treatment is limited to a certain degree in terms of accessible bone material and also requires an additional surgical intervention, which elevates the patient's morbidity and often remains painful after surgery [10-13]. In order to avoid such challenges the usage of metallic biomaterials in form of implants is required. Titanium and its alloys are often used owing to their high biocompatibility and corrosion resistance but involve the risk of implant loosening as a result of stress shielding due to the discrepancy in Young's modulus to cortical bone [14-16].

Magnesium and its alloys might conquer these difficulties since their mechanical properties are much more bone-like. Namely, its Young's modulus is closer to that of osseous tissue and due to its biodegradability it enables ingrowing bone to slowly take over the implant's space and stabilising function [17-21]. In recent years, magnesium has been proven to possess high biocompatibility in various studies $[19,22,23]$. However, the main challenge using magnesium-based implants is the gas formation due to the material's degradation process, leading to displacement of surrounding tissues and a decrease in implant-bone contact area [24,25]. A possible way to contain the initial corrosion process is to create a coating around the implant in order to shield the metallic core against the surrounding tissue fluid [26]. In the following sections the combination of a metallic basic structure and a polymeric coating is referred to as a hybrid implant. For this study we decided to coat the

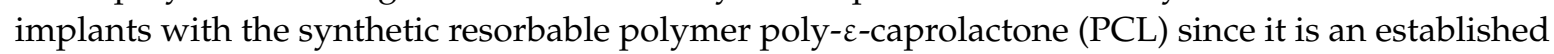
biomaterial, while at the same time showing a lowering effect on the corrosion rate of magnesium implants [27-31]. Namely, several studies prove that PCL-coating of magnesium implants leads to an increased initial corrosion resistance resulting in a decreased release of gas and a lowering of the implants' degradation rate which ultimately improves cytocompatibility for osteogenic cells [30,32,33]. In addition to the natural osteoconductive properties of magnesium, this quality can even become enhanced by creating a porous implant geometry, which allows newly formed bone tissue to grow inside the pores. Within this study, scaffold-shaped implants with a pore size of $600 \mu \mathrm{m}$ were created using the additive manufacturing process of Selective Laser Melting (SLM ${ }^{\circledR}$, Lübeck, Germany) since pore sizes of 20 to $1500 \mu \mathrm{m}$ were reported to enable an optimal osteoblast activity and therefore a sufficient osteointegration of the implant [34]. In order to enhance the latter, even further implants can be previtalised with adipose-derived mesenchymal stem cells (ADMSCs), which have become a focus of research within recent years [35]. Since they are reported to be able to differentiate into osteoblasts, they are stated to have a positive effect on bone regeneration by producing new osseous tissue [36-38]. As a high amount of ADMSCs can be isolated fast and in a minimally invasive manner from the acceptor's own adipose tissue $[39,40]$ they may be preferable over already differentiated osteoblasts for implant previtalisation.

Overall, this study deals with finding an implant material that is able to act as an alternative treatment for critically sized calvarial defects to hitherto merchantable titanium implants. Namely, it describes the local interaction of the surrounding bone tissue and the inserted hybrid implant. Therefore, the implants were tested within an in-vivo mouse model against uncoated titanium implants of the same geometry. As a negative control, mice without any implant were observed. In order to not consciously expose the animals to excessive gas production and possible side effects uncoated 
magnesium scaffolds were not used as a negative control. The uncontrolled gas production can lead to subcutaneous gas pockets, tissue necrosis, infections, alkaline poisoning and sudden death due to gas-induced embolism as stated by several studies [41-44]. To test the influence of previtalisation the hybrid implants were either populated with osteoblasts, ADMSCs or left blank. After inserting the implants within a previously set critically sized calvarial defect, bone ingrowth and implant degradation were observed via $\mu \mathrm{CT}$ scans for three months. Additionally, histomorphometrical analyses were performed to gain a closer view of the histological changes within the defect region. An enhanced amount of bone ingrowth in the hybrid implants due to the material's osteoconductivity was expected. Also, an even higher osteointegration was suggested for the previtalised implants since bone regeneration could begin not just at the defect periphery but also at the implant itself. Since the PCL-coating was created to reduce the corrosion rate of magnesium, high bone-implant contacts as well as a balanced substitution rate (defined as the quotient of implant degradation and bone ingrowth) were anticipated.

\section{Experimental Section}

\subsection{Selective Laser Melting of Titanium and Magnesium Implants}

Using the SLM technology, three-dimensional porous titanium scaffolds were manufactured by SLM $^{\circledR}$ Solutions GmbH, Lübeck, Germany. Thereby, an SLM ${ }^{\circledR} 280$ HL Selective Laser Melting machine system was utilised in order to transform Ti6Al4V powder into solid scaffolds. The magnesium implants with identical geometry were manufactured from ATOULTRA 325 pure magnesium powder (SFM SA, Martigny, Switzerland) using an SLM ${ }^{\circledR} 125 \mathrm{HL}$ machine system. All implants were post-treated using a chemical deburring process in order to create a smooth implant surface [45].

The generated implants (geometry shown in Figure 1) consisted of a $3 \mathrm{~mm} \times 3 \mathrm{~mm} \times 1.2 \mathrm{~mm}$ basic body with a pore size and strut width of $600 \mu \mathrm{m}$. To prevent the implants from sinking into the bone defect, the two outer struts of the upper implant layer were elongated at both sides 1 or $3 \mathrm{~mm}$, respectively. The longer elongated struts were bent at an angle of 15 degrees in order to ensure a proper fixation to the animal's skull.
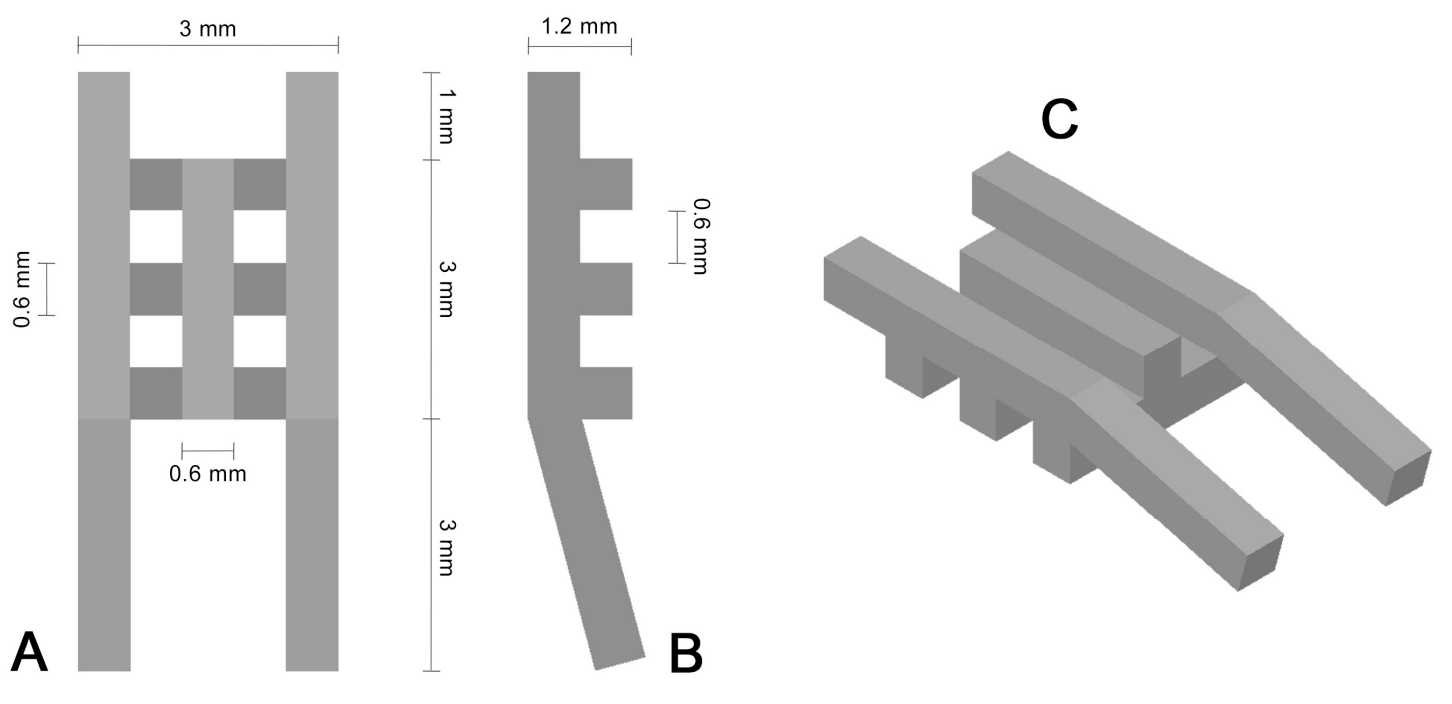

Figure 1. Schematic top view (A); side view (B) and three-dimensional view (C) of the scaffold geometry.

\subsection{PCL-Coating of Magnesium Implants}

The magnesium scaffolds were plunged 8 times into $0.8 \mathrm{wt}$. \% chloroformic (p.a. quality, J. T. Baker, Deventeer, The Netherlands) PCL ( $\mathrm{M}_{\mathrm{n}}=80.000 \mathrm{~g} / \mathrm{mol}$, Cappa 6800, Perstorp UK Limited, Warrington, $\mathrm{UK}$ ) solution using a custom-designed sample holderwith fork type tongue rings (1.5-2.5 $\mathrm{mm}$ cross 
section) to fix the samples mechanically between both forks. Between each dipping process the scaffolds were dried for $10 \mathrm{~min}$ at $23 \pm 2{ }^{\circ} \mathrm{C}$ to allow the chloroform to evaporate. After the final dipping step the scaffolds were dried at room temperature for $24 \mathrm{~h}$. For the following step the implants were carefully removed from the sample holders and both uncoated contact points were covered with $3 \mu \mathrm{L}$ of a $5 \mathrm{wt} \%$ polymer solution of PCL. Therefore, the concentration was optimised, allowing a fast bonding with the existing coating without changes in coating thickness. Afterwards, the coatings were dried for $20 \mathrm{~min}$ at room temperature. The final drying process was performed in a vacuum cabinet drier for seven days at $40{ }^{\circ} \mathrm{C}$ and 40 mbar.

\subsection{Murine Osteoblast Isolation}

Calvariae of ten C57B16 mice were grinded into small pieces which were then digested five times, each time for $10 \mathrm{~min}$ at $37^{\circ} \mathrm{C}$ in sterile Hank's medium (HBSS, PAA Laboratories GmbH, Pasching, Austria) containing $5 \mathrm{~mL}$ of $200 \mathrm{U} / \mathrm{mL}$ collagenase II (Cell Systems, Troisdorf, Germany). After each digestion step the supernatant containing diluted cells was collected and substituted with new digestion medium, resulting in a pooled cell solution of all five digestion steps. After centrifuging the solution for $7 \mathrm{~min}$ at $1200 \mathrm{RPM}$ at room temperature the cell pellet was washed twice with Dulbecco's Modified Eagle Medium (DMEM) (Biochrom AG, Berlin, Germany) containing 10\% foetal calf serum (FCS, Biochrom AG, Berlin, Germany), $20 \mathrm{mM}$ Hepes, $1000 \mathrm{IU} / \mathrm{mL}$ penicillin and $0.1 \mathrm{mg} / \mathrm{mL}$ streptomycin (both PAA, Coelbe, Germany). After resuspending the pellet the cells were seeded onto T25 tissue culture flasks (TPP, Trasadingen, Switzerland) filled with $5 \mathrm{~mL}$ DMEM containing 10\% FCS and incubated at $37{ }^{\circ} \mathrm{C}$ and $5 \% \mathrm{CO}_{2}$. The culture medium was changed twice a week and cell populations were split at $80 \%$ confluence.

\subsection{Murine ADMSC Isolation}

Inguinal fat tissue was isolated from BALB/c mice and stored in sterile Hank's medium until further processing. Afterwards, the tissue was washed three times with phosphate buffered saline (PBS, Biochrom AG, Berlin, Germany), separated from adhering connectiveand vascular tissue and shredded with a scalpel. The resulting material was then added to a tube filled with $5 \mathrm{~mL} 0.026 \%$ Collagenase solution and incubated for $1 \mathrm{~h}$ at $37^{\circ} \mathrm{C}$ while being rotated within a MACmix ${ }^{\mathrm{TM}}$ Tube Rotator (Milteny Biotec $\mathrm{GmbH}$, Bergisch Gladbach, Germany). After incubation the resulting collagenase-cell-solution was added to $5 \mathrm{~mL}$ DMEM containing 10\% FCS and centrifuged for $10 \mathrm{~min}$ at $1000 \mathrm{RPM}$ at room temperature. Before resuspending the cell pelletin $1 \mathrm{~mL}$ culture medium the supernatant was removed. The resulting collagenase-free cell solution was then added to T25 tissue culture flasks (TPP, Trasadingen, Switzerland) filled with $5 \mathrm{~mL}$ DMEM containing $10 \%$ FCS and incubated at $37{ }^{\circ} \mathrm{C}$ and $5 \%$ $\mathrm{CO}_{2}$. The culture medium was changed twice a week and cell populations were split at $80 \%$ confluence.

\subsection{Implant Previtalisation}

For previtalisation the implants were inserted into the wells of a flat bottomed 96 well plate filled with $150 \mu \mathrm{L}$ DMEM containing 10\% FCS. After trypsinating murine osteoblasts (P 1) and murine ADMSCs (P 1) from culture flasks the upfacing surfaces of each of the eight hybrid implantswere previtalised with either $25 \times 10^{3}$ osteoblasts or the same amount of ADMSCs according to Table 1 . After an attachment time of one hour under cell culture conditions $\left(37^{\circ} \mathrm{C}, 5 \% \mathrm{CO}_{2}\right)$ the implants were flipped upside down, the procedure then being repeated on the other side of the scaffold. After an additional attachment time of one hour the implants were finally stored within the wells of a 6-well plate filled with $5 \mathrm{~mL}$ DMEM containing $10 \% \mathrm{FCS}$ and kept at $37^{\circ} \mathrm{C}$ and $5 \% \mathrm{CO}_{2}$ until the following morning (day of surgery). The attachment times were set at one hour to avoid any negative effects arising from magnesium corrosion products on cellular vitality. 
Table 1. Experimental animal grouping.

\begin{tabular}{ccccc}
\hline Experimental Group Number & Surgery & Implant & Coating & Previtalisation \\
\hline Control group 1 & Defect & - & - & - \\
Control group 2 & Defect & Titanium & - & - \\
Group 3 & Defect & Magnesium & PCL & - \\
Group 4 & Defect & Magnesium & PCL & Murine Osteoblasts \\
Group 5 & Defect & Magnesium & PCL & Murine ADMSCs \\
\hline
\end{tabular}

\subsection{Animal Grouping and Treatment}

A total number of 40 eight-week-old female BALB/c mice (Charles River Laboratories, Wilmington, MA, USA) were allocated to five experimental groups of eight according to Table 1 and kept in groups of four (two cages per experimental group) in cages bedded withArbocel ${ }^{\circledR}$ comfort natural bedding material (Altromin $\mathrm{GmbH}$, Lage, Germany). Maintenance diet pellets (Altromin $\mathrm{GmbH}$ ) as well as water via polycarbonate bottles were offered ad libitum during the whole experimental period. The cages were stored in a climatic chamber (Tecniplast S.p.A., Buguggiate, Varese, Italy) in a $12 \mathrm{~h}$ day-night rhythm, checking temperature and humidity each day using a digital thermohygrometer (TFA Dostmann GmbH, Wertheim, Germany). Before surgery the mice were kept for four weeks, handling them each day to ensure a proper acclimatisation and an overall low stress level.

After surgery the animals were treated analgesically (Carprofen $5 \mathrm{mg} / \mathrm{kg}$ s.c. and Tramadol $1 \mathrm{mg} / \mathrm{mL}$ drinking water p.o. for three days) and weighed constantly in order to monitor changes in health and eating behaviour. One mouse in group 3, two mice in group 4 and three mice in group 5 rejected their implant before the second $\mu \mathrm{CT}$ scan. The resulting wounds healed properly within a few days under analgesic treatment (Tramadol $1 \mathrm{mg} / \mathrm{mL}$ drinking water for three days) without any signs of infectious inflammation and did not affect the animal's eating, drinking or comfort behaviour. Therefore, no intervention in form of early euthanasia was indicated.

\subsection{Surgical Methods}

After anaesthetising with ketamin (100 mg/kg i.p.) and xylazin (4-12 mg/kg i.p.) the skin above the implantation region was depilated, washed and disinfected. To avoid intraoperative hypothermia the animal was layed on a MouseMonitor ${ }^{\mathrm{TM}} \mathrm{S}$ warming plate (Indus Instruments, Webster, TX, USA) which ensured a constant body temperature. The entire surgery was performed under sterile conditions using a Universal S3 surgery microscope (Carl Zeiss AG, Oberkochen, Germany). The skin was cut and retracted in order to gain a proper view of the osseous calvarium. Using a diamond milling head on a MICROMOT 50/E milling machine (Proxxon $\mathrm{GmbH}$, Föhren, Germany), an approximately $3 \mathrm{~mm} \times 3 \mathrm{~mm}$ square bone platelet was milled out, while preserving surrounding blood vessels and underlying meninges. Within this process the operating area was constantly cleared and cooled with sterile saline solution in order to ensure a clear view and to avoid any heat caused by the milling process. After removing the bone platelet a magnesium or titanium implant was inserted in the created defect according to the animal group number as described in 2.6. To avoid both damage to the meninges due to the implant sinking into the defect and implant shifting during the experiment, the elongated struts were attached to the opposite side of the calvarium using an ethyl-2-cyanoacrylate-based tissue glue (EPIGLU ${ }^{\circledR}$, Meyer-Haake Medical Innovations, Ober-Mörlen, Germany). Thereafter, the skin was sutured with resorbable sewing material. In the case of control group 1 the skin was closed in a similar manner but without inserting any implant. After the following first $\mu \mathrm{CT}$ scan the mice were treated analgesically with Carprofen $(5 \mathrm{mg} / \mathrm{kg}$ s.c.) and received a subcutaneous saline infusion while lying under an infrared lamp to ensure a safe and proper recovery. 


\section{8. $\mu \mathrm{CT}$ Scans and Data Analysis}

All $\mu \mathrm{CT}$ scans were performed using an XtremeCT (Scanco Medical AG, Brüttisellen, Switzerland) with a fixed tube voltage of $60 \mathrm{kV}$. The resolution and integration time were set at $41 \mu \mathrm{m}$ and $700 \mathrm{~ms}$, respectively. In order to reduce anaesthesia time especially at the first scan right after surgery, only a small part of approximately $9 \mathrm{~mm}$ of the skull was scanned. Therefore, each scan lasted about $15 \mathrm{~min}$ and contained 220 slices.

To evaluate the absorbed dose per mouse during one $\mu \mathrm{CT}$ scan a cylindric acrylic glass body (Figure 2) with small cavities for lithium-fluoride thermoluminescent dosimeter (TLD) (TLD-100H, Thermo Fisher Scientific, Waltham, MA, USA) was used as a mouse phantom. The phantom was scanned with the same parameters that were used for the actual experimental scans.

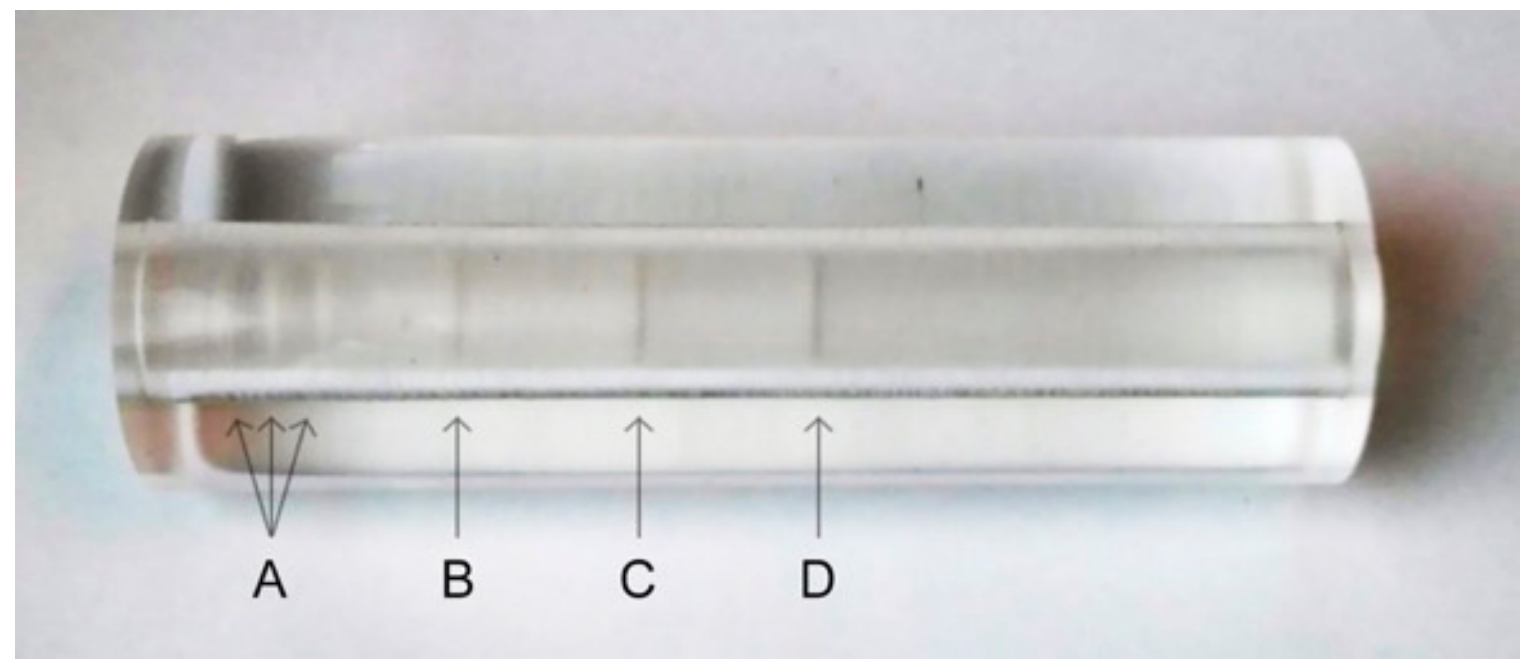

Figure 2. Two-piece acrylic glass mouse phantom (diameter: $3 \mathrm{~cm}$; length: $10 \mathrm{~cm}$ ). The inner pin (diameter: $1 \mathrm{~cm}$ ) contains six cavities for one TLD each for measuring the exposure during the $\mu \mathrm{CT}$ scans. Three cavities were placed within $1 \mathrm{~cm}$ (head region of the mouse; (A) and the others at a distance of $2 \mathrm{~cm}$ (lung; (B)); $3.5 \mathrm{~cm}$ (kidney; (C)) and $5 \mathrm{~cm}$ (abdomen; (D)) from the first cavity.

The resulting scan data were evaluated using the Amira 3D visualisation and analysis software (version 5.5.0, FEI Visualization Sciences Group, Hillsboro, OR, USA). Primarily, the threshold was set at 450 Hounsfield Units (HU) to separate soft from bony tissue. Since they showed similar HU, both magnesium implants and bone tissue were detected within the same threshold range. Nevertheless, both structures were determined separately due to the characteristic implant geometry. Next, the bone defect of the first scan (day 0, Figure 3A) was cut out manually so only a fine rim of bone remained around the defect (Figure $3 \mathrm{~B}$ ). This shape was then used as a blueprint and projected on the skulls in scans of day 28 (Figure 3C,D), 56 and 84 respectively to cut out the exact same region of interest (ROI, starting point of defect healing, Figure 3E). Afterwards, the volume of the bone around the defects was calculated automatically.

For examining the contralateral side, acuboid ROI of $3.7 \mathrm{~mm} \times 3.7 \mathrm{~mm} \times 2.0 \mathrm{~mm}$ was placed in the middle of the left calvaria side and analysed regarding bone volume in a similar manner to the treated side. Since the titanium implants unfortunately caused massive artefacts in the $\mu \mathrm{CT}$ scans there was no possibility of analysing the bone ingrowth in control group 2 .

Regarding the magnesium implant degradation, the analysing process followed the same steps but used another ROI around the scaffold. For each group, the average values for both defect healing and implant degradation were determined for every scanning day. 

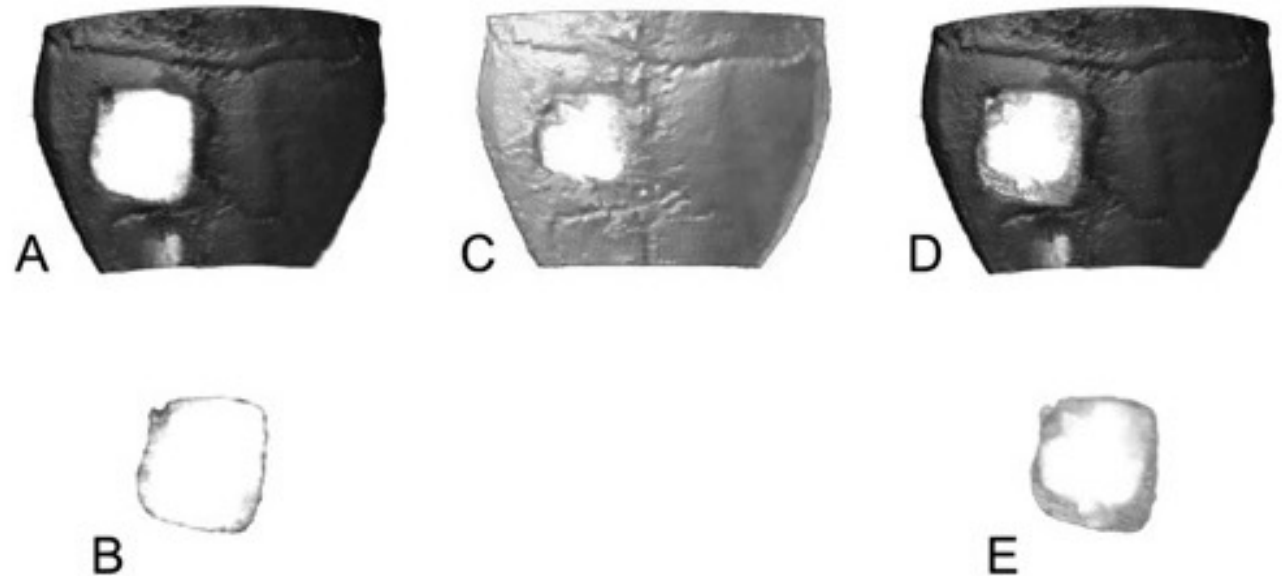

Figure 3. $\mu \mathrm{CT}$ scans of the skull. Dorsal view at the calvaria of a mouse from control group 1 at day 0 (A) and the (cut out ROI (B); Same view at day 28 without (C) and with overlaid first scan (D) resulting in the ROI for day $28(\mathrm{E}))$.

\subsection{Preparation of Histological Thin Sections}

After the final $\mu \mathrm{CT}$ scan at day 84 the mice were euthanised in anaesthesia using $0.15 \mathrm{~mL}$ pentobarbital i.p. and decapitated after ensuring death by heart beat absence. Before commencing the dehydration procedure for technovit embedding, the heads were stored in $4 \%$ formaldehyde. The dehydration process was performed using decreasing alcohol concentrations followed by embedding in technovit $9100 \mathrm{Neu}$. Resulting technovit blocks were cut into thin sections using a diamond band saw (EXAKT Advanced Technologies GmbH, Norderstedt, Germany). Afterwards, the thin sections were grinded and polished by a lap-grinder grinding machine (patho-service $\mathrm{GmbH}$, Oststeinbeck, Germany) in order to achieve sections of about $30 \mu \mathrm{m}$ thickness. To achieve a high contrast between mineralised bone tissue and newly formed osteoid, trichrome-masson-goldner staining was performed. Afterwards, the stained and Eukitt-covered thin sections were photographed with the computer-controlled microscope Axio Imager.Z1 (Carl Zeiss AG, Oberkochen, Germany) using the AxioVision SE64 software (version 4.9.1.0; Carl Zeiss AG, Oberkochen, Germany). All examined images can be found in the Supplementary Materials (Figures S2-S124).

\subsection{Histomorphometrical Analysis}

Using the thresholding function of ImageJ picture analysis software, the images (Figure 4A) were separated into different colour ranges. While mineralised bone tissue was stained in bright turquoise and therefore easily detectable, the osteoid seams shared their orange colouration with fibrotic capsule strings as well as muscular and connective tissue of the overlaying skin. Since only newly formed bone tissue should be analysed, the unwanted structures were identified due to their characteristic morphological and cellular structure and deleted before analysis. The resulting single images for mineralised (Figure 4B) and unmineralised (Figure 4C) bone tissue were then analysed separately and also combined (Figure 4D) regarding their surface area using the program's thresholding and measuring function. Therefore, the total bone area per slide was determined as well as the percentage proportion of osteoid.

As a parameter of defect regeneration the total amount of intraosteal blood vessels was counted for each section. This and all previously described measurements were performed for both the left and the right side of the skull in order to compare the defect (and possibly implant) treated right side with the untreated left side. Since the implants were attached to the left side of the skull possible influences of this anchoring could also be analysed. 


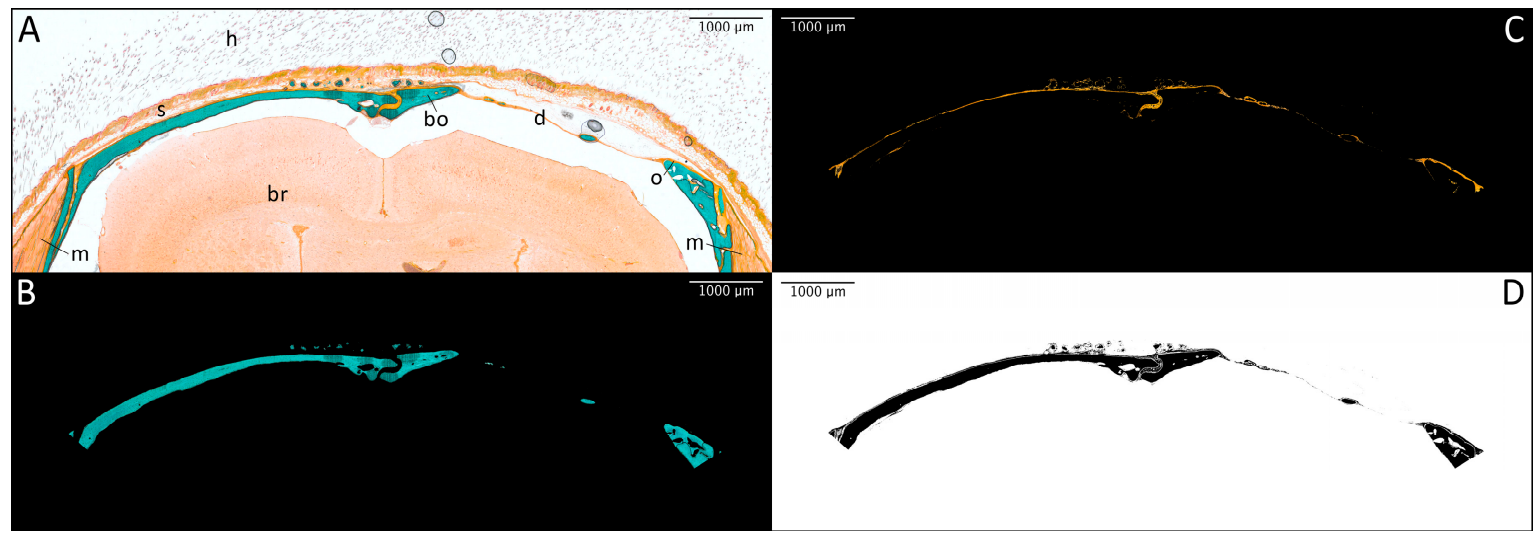

Figure 4. Laterolateral thin section of a mouse without an implant after trichrome-masson-goldner staining ((A); bo = mineralised bone tissue, $\mathrm{br}=$ brain, $\mathrm{d}=$ defect, $\mathrm{h}=$ hair, $\mathrm{m}=$ muscle tissue, $\mathrm{o}=$ osteoid seam, $\mathrm{s}=$ skin; 10-fold magnification); mineralised bone tissue (turquoise) after thresholding (B); osteoid (orange) after thresholding and subtracting fibrotic and muscular tissue (C); double-thresholded total bone area (black $=$ mineralised bone tissue + osteoid) ready for analysis $(\mathbf{D})$.

In order to evaluate the implant bone interaction, the titanium implants were thresholded (Figure 5B) and their surface length was determined. Unfortunately, the staining process caused the dissolution of the magnesium implants, but by using pre-staining photographs (Figure 5C) the implants could be reconstructed and analysed in a manner similar to titanium ones (Figure 5E). After measuring the implant surface length, the single pictures for mineralised bone tissue, osteoid and implant material were overlayed and the length of the contact surfaces was measured, resulting in the percentage values of implant bone contact.

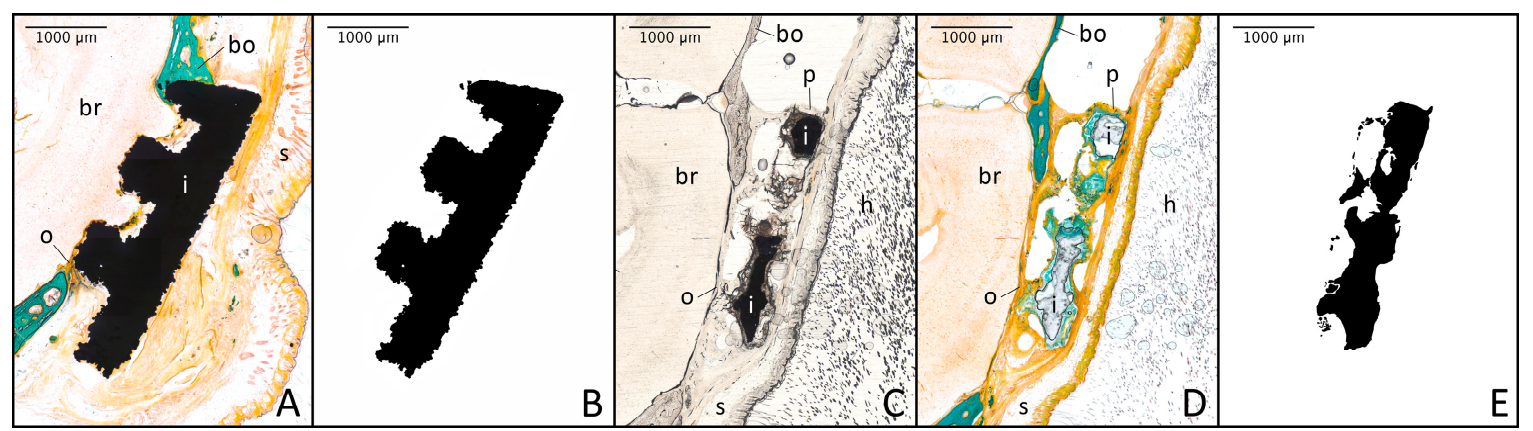

Figure 5. Laterolateral thin section of a mouse treated with an uncoated titanium implant (A) or an PCL-coated magnesium implant (C,D) before (C) or after trichrome-masson-goldner staining ((A,D); bo $=$ mineralised bone tissue, $\mathrm{br}=$ brain, $\mathrm{h}=$ hair, $\mathrm{i}=$ implant in the defect, $\mathrm{o}=$ osteoid, $\mathrm{p}=\mathrm{PCL}$, $\mathrm{s}=$ skin; 10-fold magnification); thresholded uncoated titanium implant (B) or manually reconstructed PCL-coated magnesium implant (E) ready for analysis.

\subsection{Statistical Analysis}

Statistical analyses of data were performed using SAS ${ }^{\circledR}$ software (version 9.3, SAS Institute Inc., Cary, NC, USA). Type I error was set at $5 \%$ so p-values below 0.05 were considered statistically significant. Since the entire data were normally distributed the Ryan-Einot-Gabriel-Welsh Multiple Range test and the two-sample t-test were performed to detect significant differences between the experimental groups. Regarding the comparison of the different times of observation within each group, analyses of variance (ANOVA) for repeated measurements were performed. In this regard only successive observation times were compared to one another. In general, outliers were defined as values lying more than 1.5 times the interquatile range away from the upper or the lower quartile. 


\section{Results}

The median values as well as the standard deviations for bone volume, implant degradation, bone area, osteoid and blood vessel measurement can be found in Supplementary Materials (Table S1).

\subsection{Evaluation of $\mu \mathrm{CT}$ Scans}

\subsubsection{Radiation Exposure}

The evaluation of the TLDs showed that each mouse was exposed to an absorbed dose of about $30 \mathrm{mGy}$ per scan at the head region, $2.4 \mathrm{mGy}$ at the lung, $0.7 \mathrm{mGy}$ at the kidneys and $0.4 \mathrm{mGy}$ at the abdomen, respectively.

\subsubsection{Bone Volume}

Judging from the $\mu \mathrm{CT}$ scans for each measurement day, semiquantitatively the largest increase in bone volume took place between days 0 and 28 for each experimental group, while within the subsequent scans the defects of each group appeared to remain stable. Figure 6 exemplarily illustrates this development in bone volume increase for control group 1 (without implant) as well as for the groups 3 to 5 . Since titanium caused massive artefacts in the $\mu \mathrm{CT}$ images (see Supplementary Materials Figure S1 for an exemplary image) demarcation of the implant to the defect and therefore an observation of the defect closure were not possible within this experiment.

A

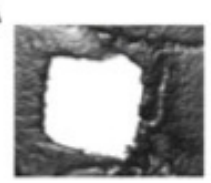

E

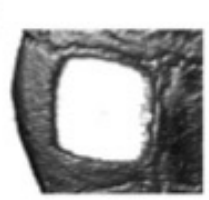

I

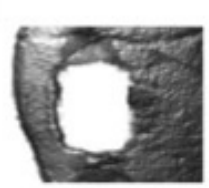

M

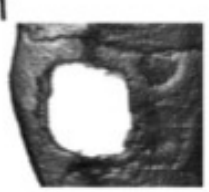

B

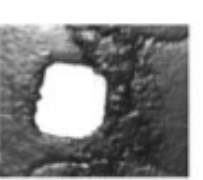

$\mathrm{F}$

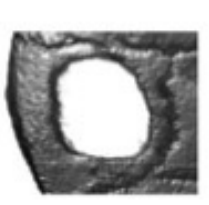

J

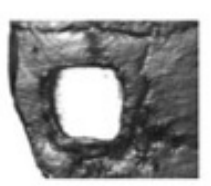

$\mathrm{N}$

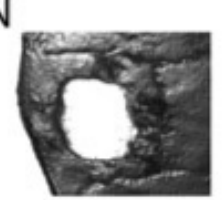

C

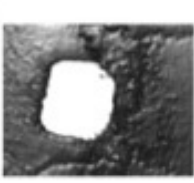

G

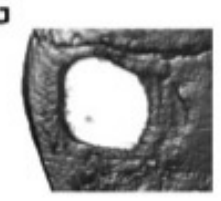

K

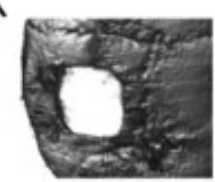

0

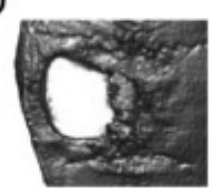

D

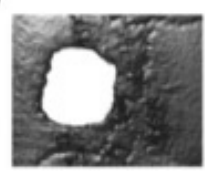

$\mathrm{H}$

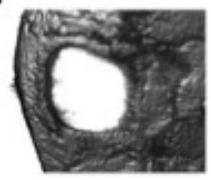

$\mathrm{L}$

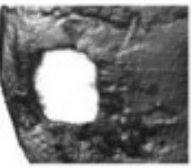

$\mathrm{P}$

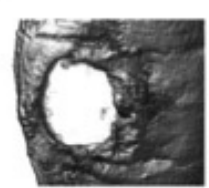

Figure 6. Top view of representative $\mu \mathrm{CT}$ scans of the defect of control group 1 (without implant; (A-D)) as well as group 3 (hybrid implant; (E-H)), group 4 (hybrid implant + murine osteoblasts; (I-L)) and group 5 (hybrid implant + mADMSCs; (M-P)) at days $0(\mathbf{A}, \mathbf{E}, \mathbf{I}, \mathbf{M}), 28(\mathbf{B}, \mathbf{F}, \mathbf{J}, \mathbf{N}), 56(\mathbf{C}, \mathbf{G}, \mathbf{K}, \mathbf{O})$ and $84(\mathbf{D}, \mathbf{H}, \mathbf{L}, \mathbf{P})$. For any other but the control group the implant was cut out in order to have a proper view of the defect.

At day 0 there were no significant differences in bone volume between the different groups on the treated skull side, this emphasising the high amount of accuracy put into creating the surgical defect (Figure 7, lower row). All groups showed a significant increase in bone volume between days 0 and 
28 (Figure 8, lower row; without implant: $p<0.0001$; Mg-PCL: $p=0.0003$; Mg-PCL + mOsteoblasts: $p<0.0001 ; \mathrm{Mg}-\mathrm{PCL}+\mathrm{mADMSCs}: p=0.0033)$. Neither between the subsequent measurement days for each experimental group (Figure 8, lower row) nor between the groups at each measured time (Figure 7, lower row) could significant differences in bone volume formation be detected.

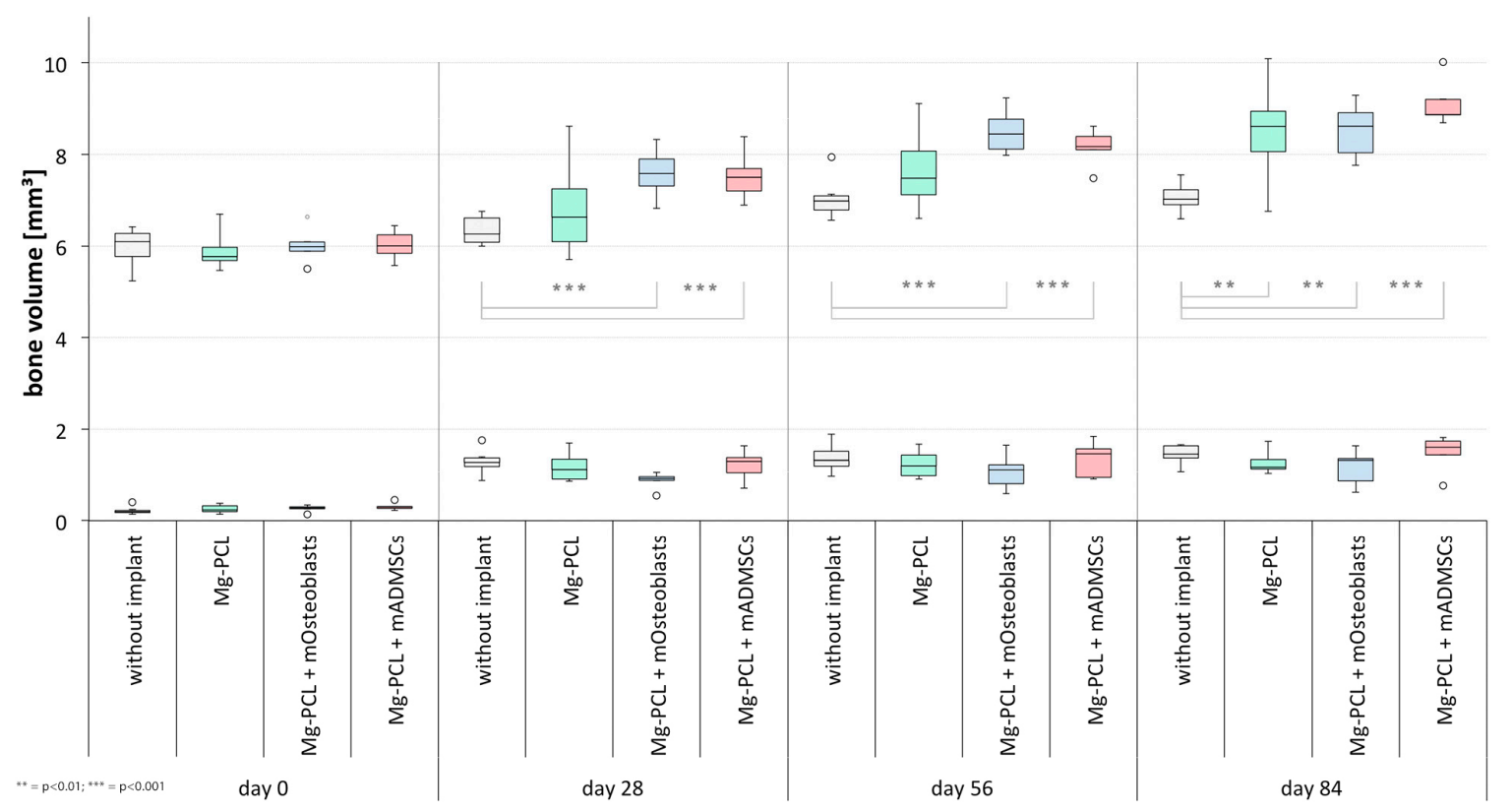

Figure 7. Comparative presentation of the formation of bone volume on the defect treated right side (lower row) and untreated left side (upper row) between the experimental groups at days 0, 28, 56 and $84\left(^{* *}=p<0.01 ;{ }^{* * *}=p<0.001\right.$; whiskers = minimal and maximal values; horizontal line = median; circles $=$ outliers).

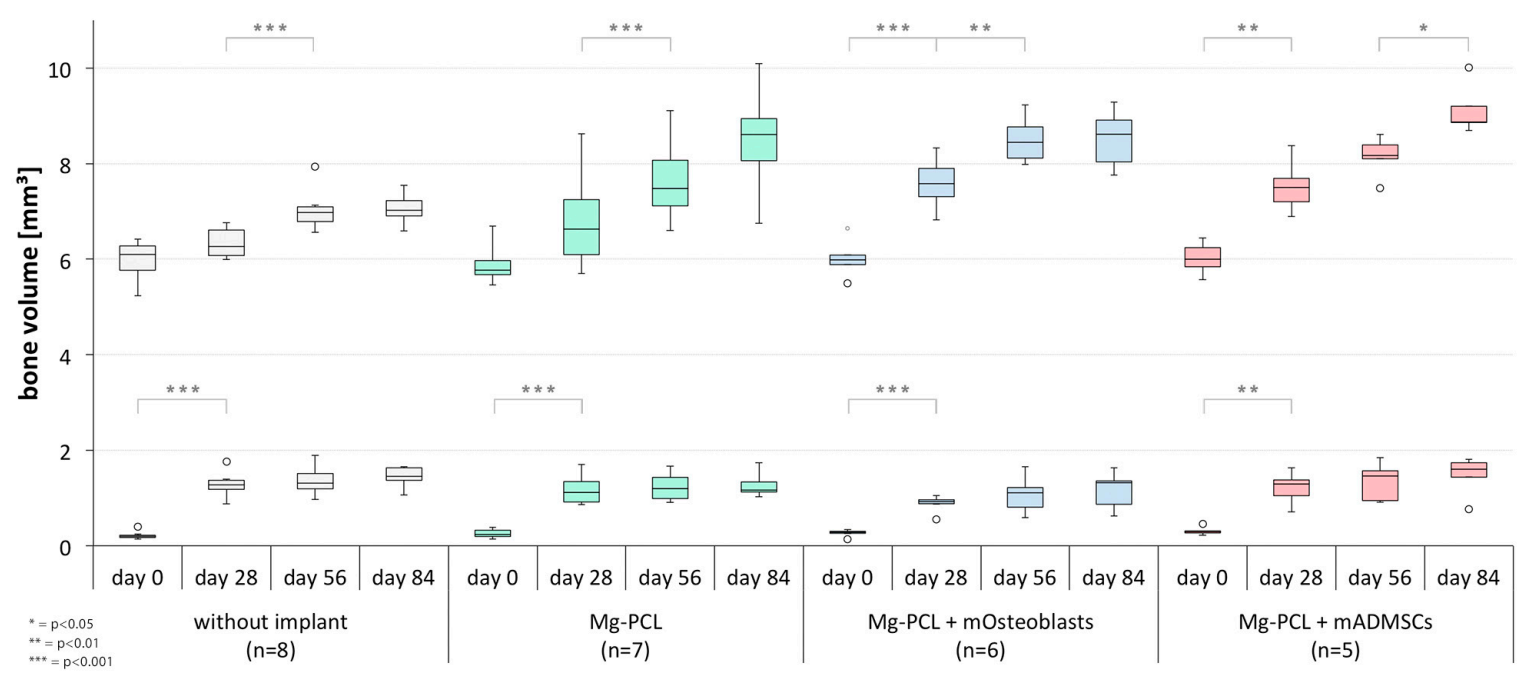

Figure 8. Comparative presentation of the formation of bone volume on the defect treated right side (lower row) and untreated left side (upper row) between the different measurement times within each experimental group $\left({ }^{*}=p<0.05 ;{ }^{* *}=p<0.01 ;{ }^{* * *}=p<0.001\right.$; whiskers $=$ minimal and maximal values; horizontal line $=$ median; circles $=$ outliers $)$.

However, on the untreated left side significant differences in bone volume could be revealed between control group 1 (only defect) and both Mg-PCL treated groups previtalised with mOsteoblasts or mADMSCs at days 28 (Mg-PCL + mOsteoblasts: $p=0.0001$; Mg-PCL + mADMSCs $p=0.0007$ ), 
56 (Mg-PCL + mOsteoblasts: $p<0.0001 ;$ Mg-PCL + mADMSCs $p=0.0007)$ and 84 (both $p<0.0001$ ). At day 84 there was also a significant difference in bone volume between control group 1 and the non-previtalised MG-PCL group ( $p=0.0031$; Figure 7 upper row).

Regarding the bone volume development between the different measurement times (Figure 8 , upper row) significant differences could be detected between days 28 and 56 within control group 1 $(p=0.0004)$ as well as within the non-previtalised Mg-PCL group $(p=0.0003)$ and the Mg-PCL group previtalised with mOsteoblasts $(p=0.0064)$. Additionally, there were significant differences between days 0 and 28 for both previtalised Mg-PCL groups (mOsteoblasts: $p=0.0009$; mADMSCs: $p=0.0069$ ). Within the Mg-PCL group previtalised with mADMSCs also a significant difference in bone volume formation could be detected between days 56 and $84(p=0.0338)$.

\subsubsection{Implant Degradation}

Judging from the $\mu \mathrm{CT}$ scans for each measurement day, semiquantitatively the magnesium implant volume decreased consistently during the 84 days of observation (Figure 9). The degradation process pertained at first the bars facing the defect (cf. Figure 5C-E). Figure 9 exemplarily illustrates this development in implant degradation for non-previtalised magnesium implants.

A

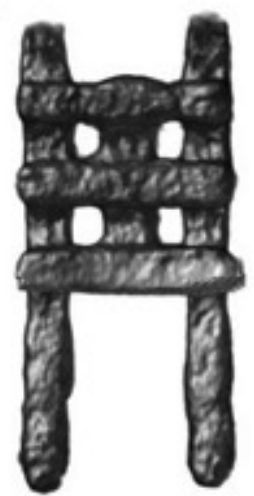

$\mathrm{E}$

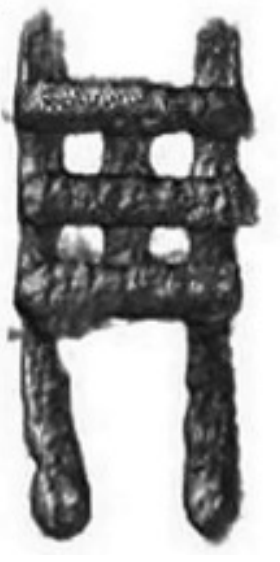

B

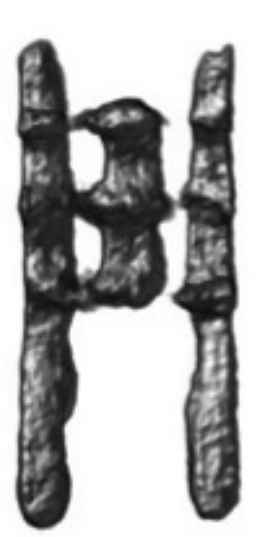

F

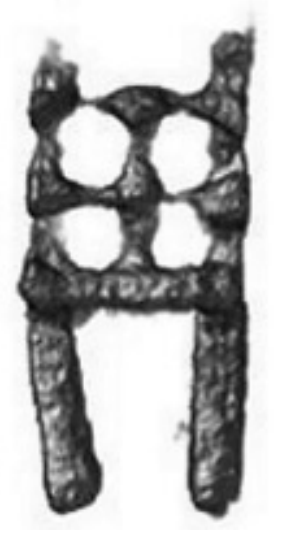

C
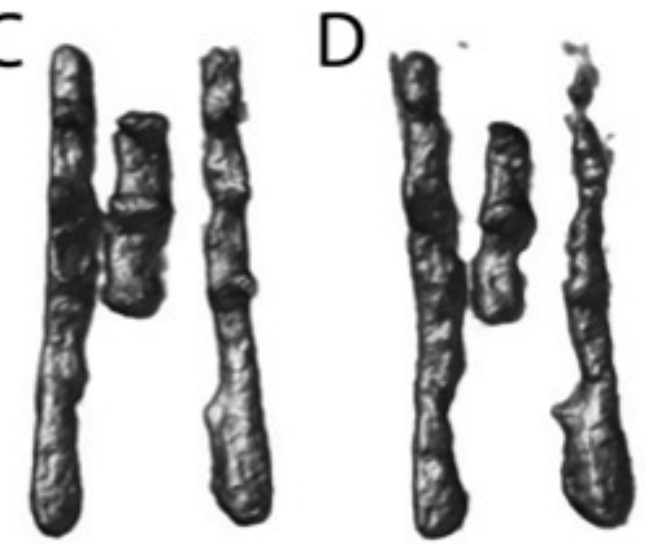

G

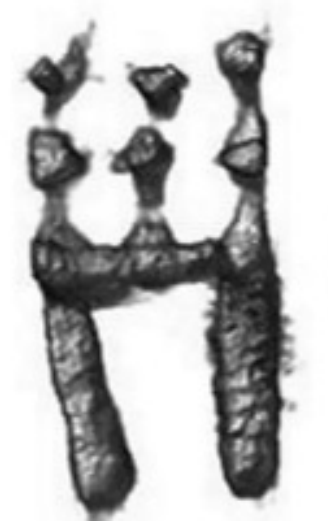

$\mathrm{H}$

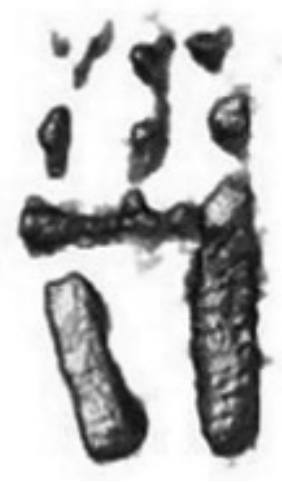

Figure 9. Cont. 
I

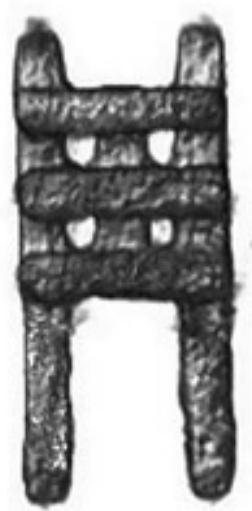

J

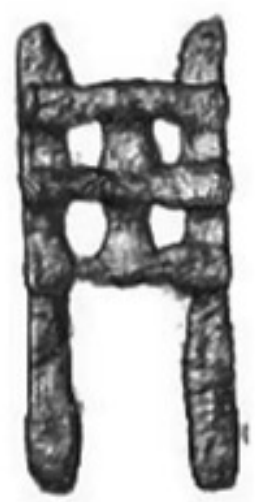

$\mathrm{K}$

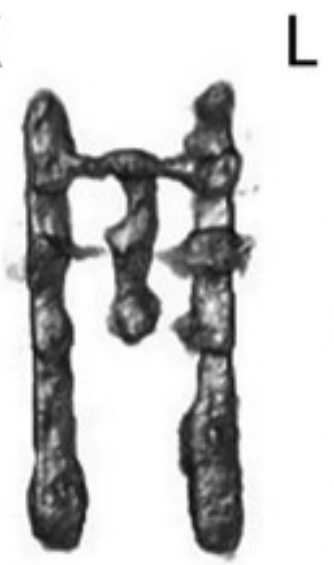

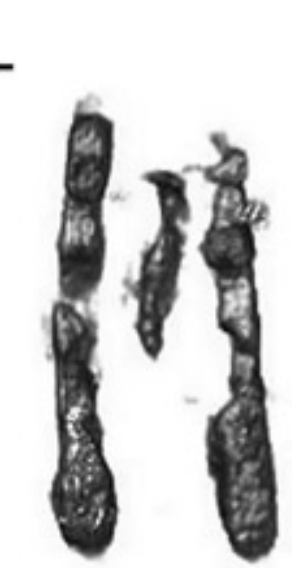

Figure 9. Top view of representative $\mu \mathrm{CT}$ scans of Mg-PCL implants without previtalisation (A-D), or previtalised with either murine osteoblasts $(\mathbf{E}-\mathbf{H})$ or mADMSCs $(\mathbf{I}-\mathbf{L})$ at days $0(\mathbf{A}, \mathbf{E}, \mathbf{I}), 28(\mathbf{B}, \mathbf{F}, \mathbf{J}), 56(\mathbf{C}, \mathbf{G}, \mathbf{K})$ and $84(\mathbf{D}, \mathbf{H}, \mathbf{L})$.

Within each group a significant decrease in implant volume was detected from scan to scan (Figure 10) (Mg-PCL: days 0 to 28: $p=0.0052$, days 28 to 56: $p<0.0001$, days 56 to 84: $p=0.0004$; Mg-PCL + mOsteoblasts: days 0 to 28: $p=0.0004$, days 28 to 56: $p=0.0010$, days 56 to 84: $p<0.0001$; Mg-PCL + mADMSCs: days 0 to 28: $p=0.0011$, days 28 to 56: $p=0.0114$, days 56 to 84: $p=0.0036$ ). However, between the groups there was no significant difference in implant degradation.

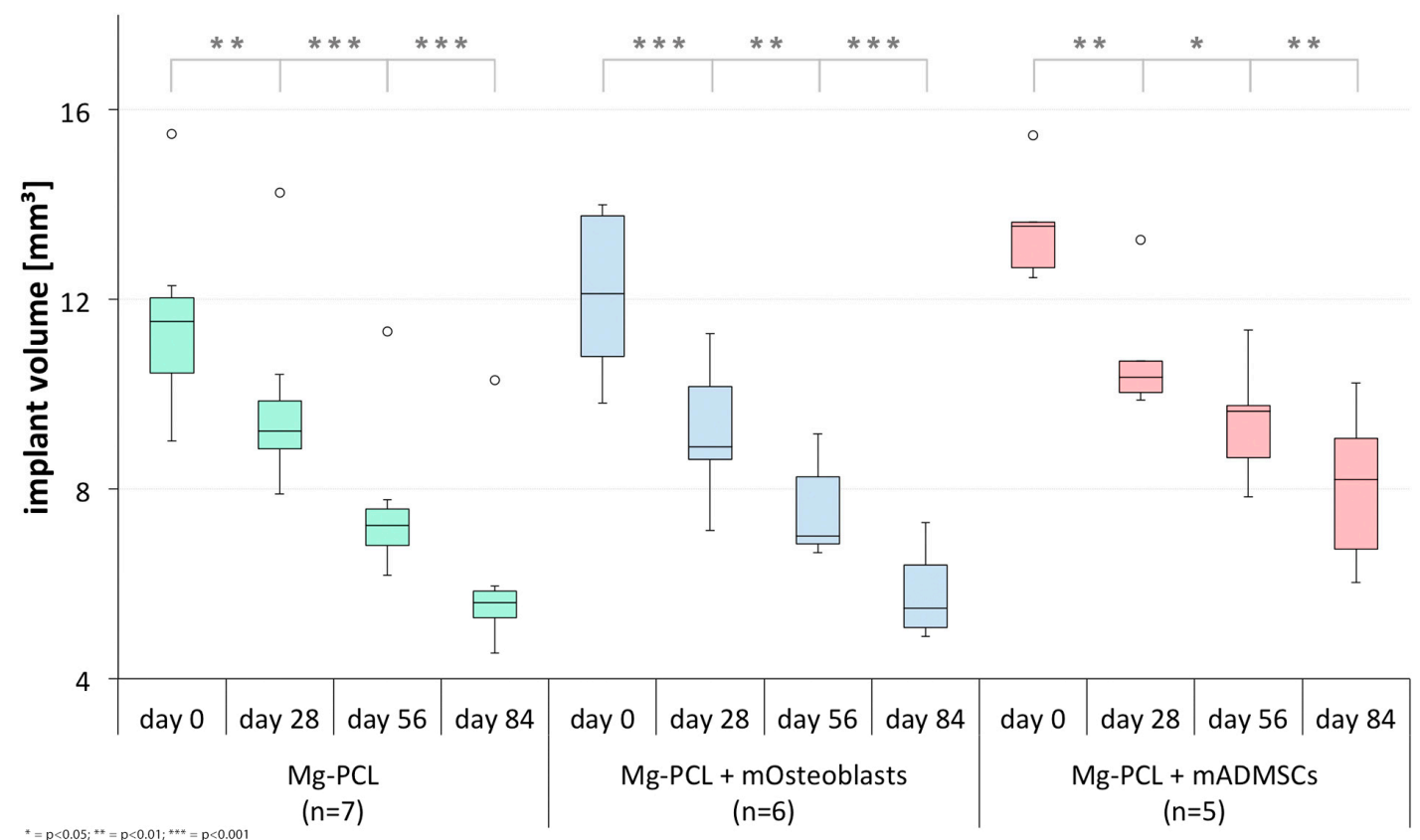

Figure 10. Comparative presentation of the implant degradation between the different measurement times within each magnesium implant-treated group $\left({ }^{*}=p<0.05 ;{ }^{* *}=p<0.01\right.$; ${ }^{* * *}=p<0.001$; whiskers $=$ minimal and maximal values; horizontal line = median; circles $=$ outliers $)$.

\subsubsection{Substitution Index}

The median substitution index (quotient of total implant volume decrease and total bone volume increase) amounted to 4.670 for the Mg-PCL implant treated group $(n=7$; standard deviation $=\mathrm{sd}=1.057)$, 6.156 for the Mg-PCL implant treated group previtalised with mOsteoblasts $(n=6 ; \mathrm{sd}=0.908)$ and 6.286 for the Mg-PCL implant treated group previtalised with mADMSCs $(n=5$; sd $=3.908$; Figure 11). 


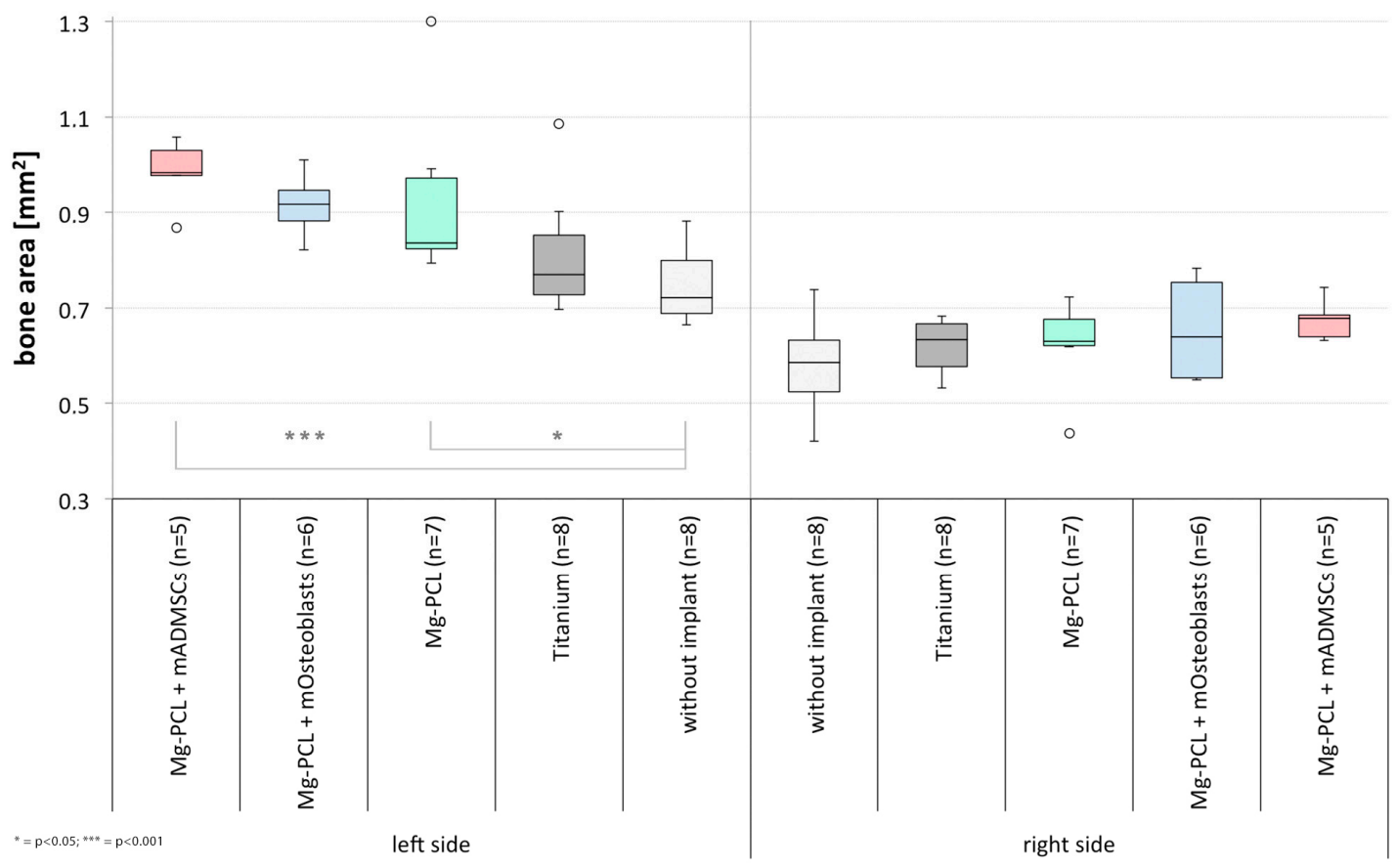

Figure 11. Measured bone area on slides of mice treated without an implant, with uncoated titanium implants, non-previtalised Mg-PCL implants and Mg-PCL implants previtalised with either mOsteoblasts or mADMSCs for both skull halves $\left({ }^{*}=p<0.05 ;{ }^{* * *}=p<0.001\right.$; whiskers $=$ minimal and maximal values; horizontal line = median; circles $=$ outliers $)$.

\subsection{Histomorphometry}

\subsubsection{Bone Area}

On the possibly implant-treated right side of the skull no significant differences between the experimental groups could be observed (Figure 11). However, on the untreated left half significantly higher amounts of bone could be found in the groups treated with non-previtalised Mg-PCL implants or the ones previtalised with mADMSCs in comparison to control group 1 (Mg-PCL: $p=0.0181$; Mg-PCL + mADMSCs: $p=0.0002$ ).

\subsubsection{Proportion of Osteoid on Total Bone Tissue}

Neither on the left nor on the right skull half could significant differences between the tested groups be observed regarding the amount of newly produced bone tissue (Figure 12). When comparing the values for both sides within each group, also no significant differences could be detected.

\subsubsection{Intraosteal Blood Vessels}

On both the treated and untreated skull half a significant increase in the number of blood vessels could be found for each implant-treated group (regardless of the implant material, coating or previtalisation status) in comparison to control group 1 (without implant) apart from titanium on the left side (Figure 13; left side: Mg-PCL: $p<0.0001$, Mg-PCL + mOsteoblasts: $p<0.0001$, Mg-PCL + mADMSCs: $p<0.0001$; right side: Ti: $p=0.0015$, Mg-PCL: $p=0.0087$, Mg-PCL + mOsteoblasts: $p<0.0001$, Mg-PCL + mADMSCs: $p<0.0001)$. Also, significantly higher values could be observed for both previtalised Mg-PCL-implant-treated groups in comparison to control group 2 (Titanium) on both sides (left side: Mg-PCL + mOsteoblasts: $p<0.0001$, Mg-PCL + mADMSCs: $p=0.0002$; right side: $\mathrm{Mg}-\mathrm{PCL}+$ mOsteoblasts: $p=0.0089, \mathrm{Mg}-\mathrm{PCL}+\mathrm{mADMSC}: p=0.0018)$ and also for the non-previtalised Mg-PCL-treated group on the left skull half $(p=0.0041)$. Additionally, a significant 
decrease in blood vessels was shown for the Mg-PCL-treated group previtalised with mADMSCs in comparison to the non-previtalised Mg-PCL-treated group on the right skull half ( $p=0.0216$ ).

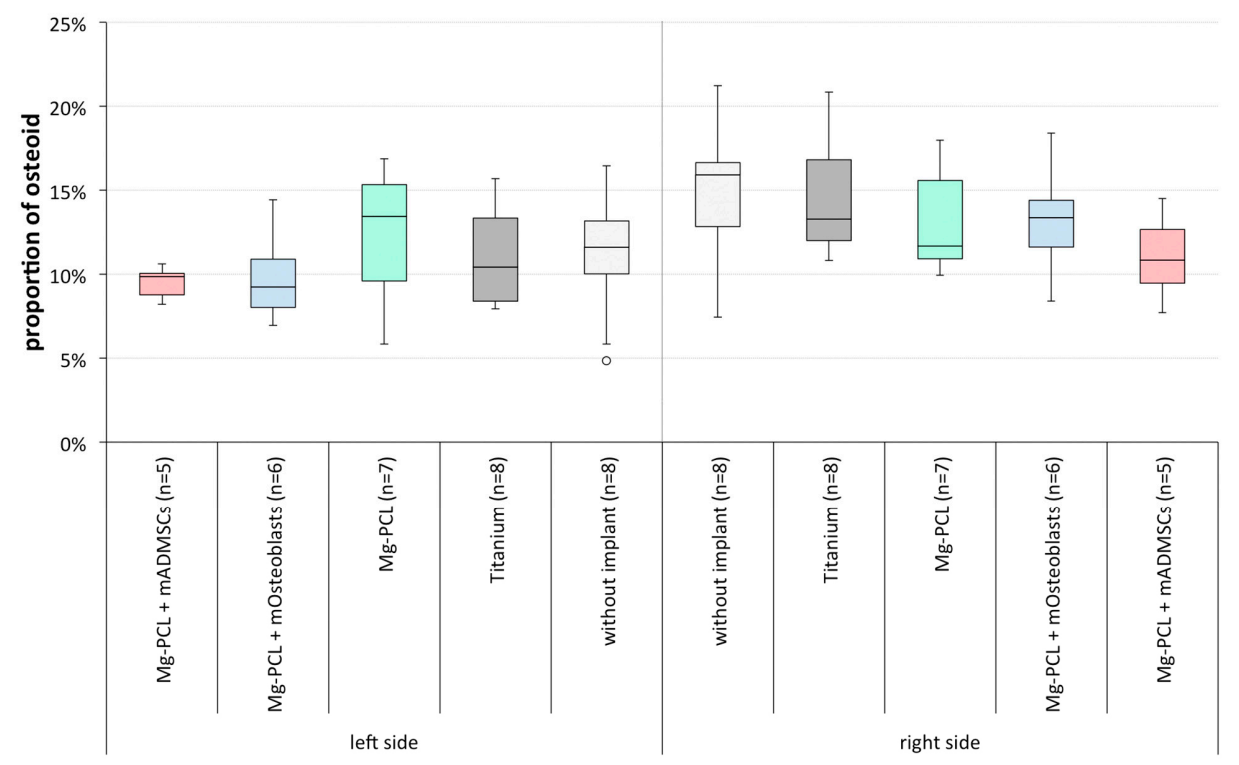

Figure 12. Proportion of osteoid on the total bone tissue (\%) on slides of mice treated without an implant, with uncoated titanium implants, non-previtalised Mg-PCL implants and Mg-PCL implants previtalised with either mOsteoblasts or mADMSCs for both skull halves (whiskers = minimal and maximal values; horizontal line $=$ median; circles $=$ outliers $)$.

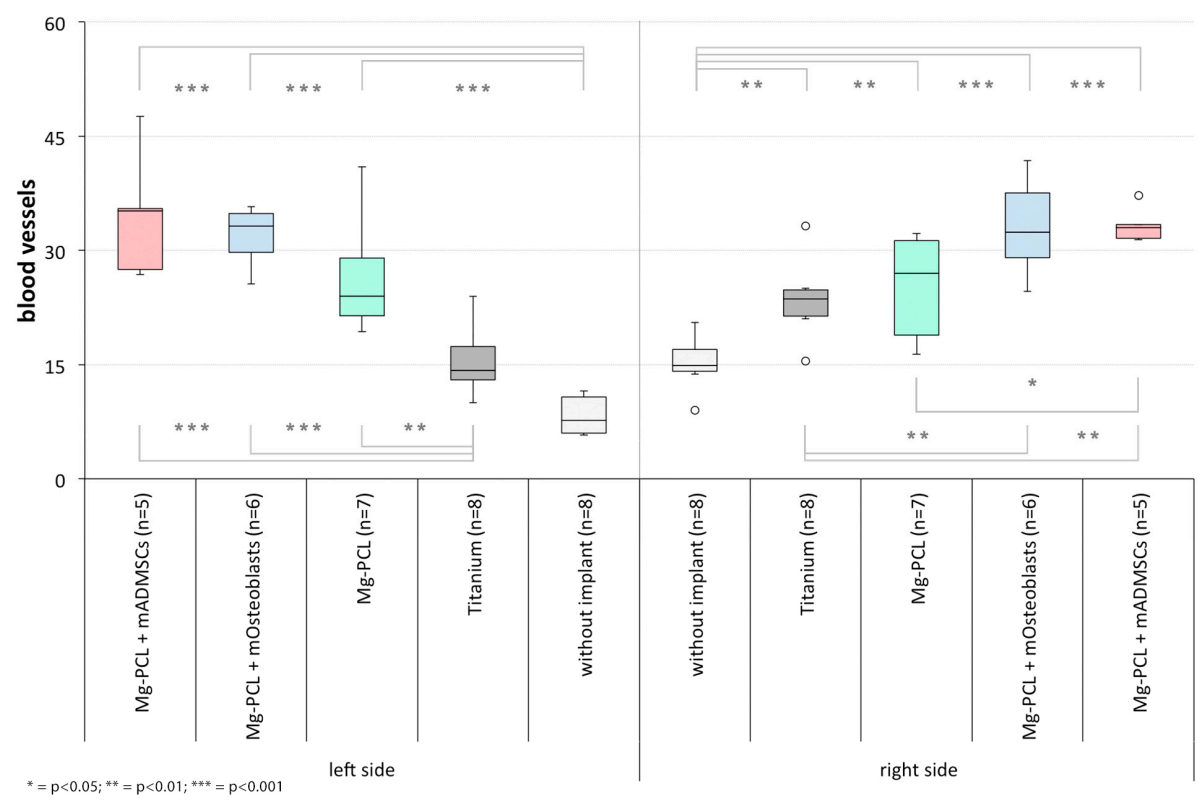

Figure 13. Counted intraosteal blood vessels on slides of mice treated without an implant, with uncoated titanium implants, non-previtalised Mg-PCL implants and Mg-PCL implants previtalised with either mOsteoblasts or mADMSCs for both skull halves $\left(^{*}=p<0.05 ;^{* *}=p<0.01 ;{ }^{* * *}=p<0.001\right.$; whiskers $=$ minimal and maximal values; horizontal line $=$ median; circles $=$ outliers $)$.

When comparing the counted blood vessels on both skull sides with each other within each experimental group, significant differences could only be detected for both control groups (Figure 14; without implant: $p=0.0003$; Ti: $p=0.0047$ ). 


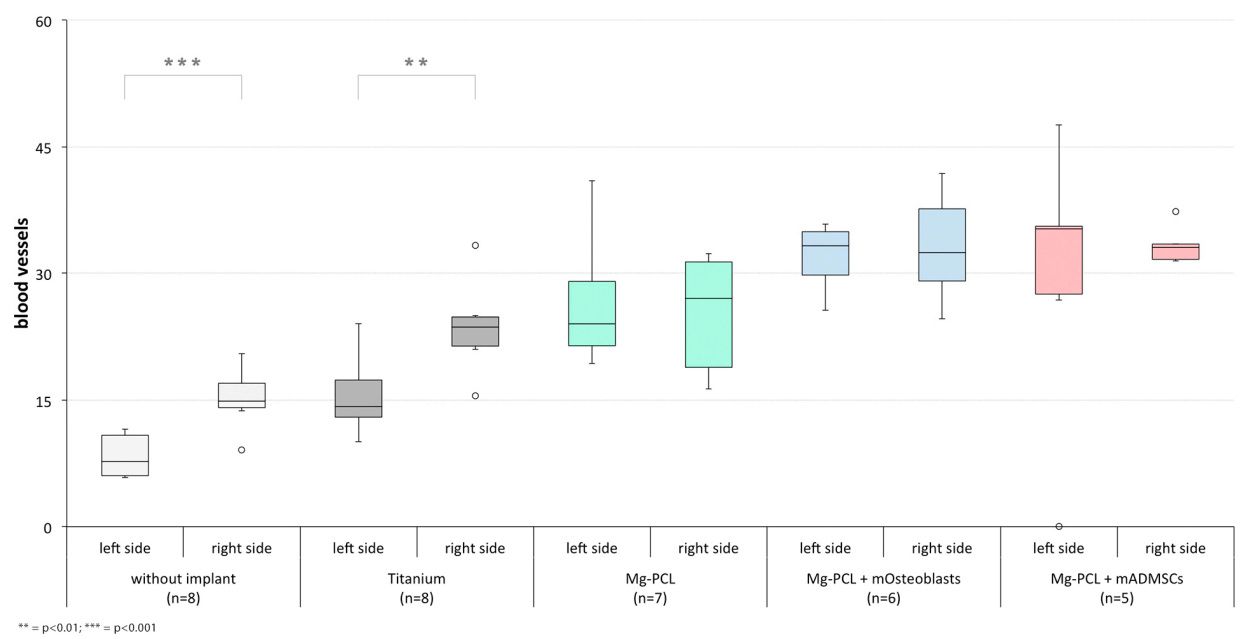

Figure 14. Comparison of counted intraosteal blood vessels of both skull sides within each experimental group (without an implant, with uncoated titanium implants, non-previtalised Mg-PCL implants and Mg-PCL implants previtalised with either mOsteoblasts or mADMSCs; ${ }^{* *}=p<0.01 ;{ }^{* *}=p<0.001$; whiskers $=$ minimal and maximal values; horizontal line $=$ median; circles $=$ outliers $)$.

\subsubsection{Implant Bone Contact}

Overall, the hybrid implants showed less bone contact in comparison to the titanium group. Within all implant treated groups there was found a tissue-free space between the elongated fixation struts and the bony anchoring area (Figure 15). While the titanium implants continued to adhere to the defect, resulting in a tighter connection to the calvarial bone, the hybrid implants were located at certain distances from the defect, causing the tissue-free space to enlarge. The surface of the hybrid implants facing the defect were surrounded by rather cellular connective tissue, but no mineralised bone could be found in direct contact to the implant regardless of the previtalisation status. The median value regarding the percentage implant bone contact for the titanium implant treated group was $6.25 \%$ ( $\mathrm{sd}=4.77 \%$ ), while it was significantly lower for each Mg-PCL-treated group regardless of the previtalisation status (Figure 16; Mg-PCL: median $=2.11 \%$, sd $=2.45 \%, p=0.0128 ; \mathrm{Mg}-\mathrm{PCL}+$ mOsteoblasts: median= 0.53\%, sd $=0.76 \%$, $p=0.0032 ; \mathrm{Mg}-\mathrm{PCL}+\mathrm{mADMSC}$ : median $=1.00 \%, \mathrm{sd}=2.03 \%, p=0.0154)$.

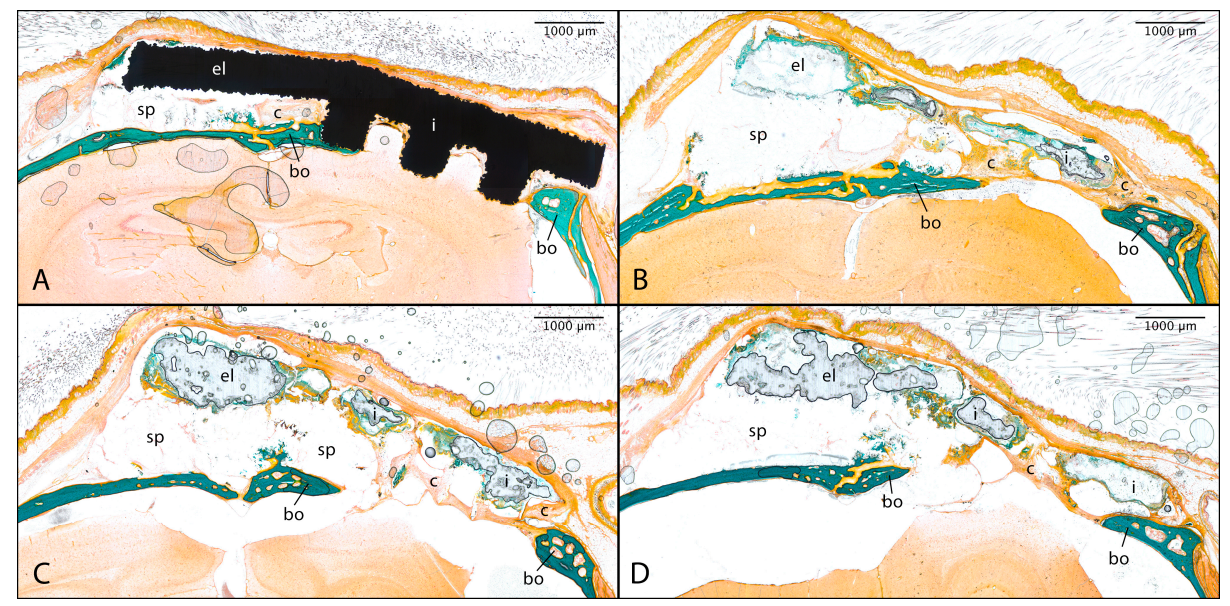

Figure 15. Representative histological images of the implant bone contact after 84 days for mice treated with either uncoated Ti6Al4V implants (A) or PCL-coated magnesium implants without previtalisation (B) or previtalised with murine osteoblasts (C) or mADMSCs (D). The magnesium implants appear to be dissolved after trichrome-masson-goldner staining ( $\mathrm{bo}=$ bone tissue, $\mathrm{c}=$ connective tissue, el = elongated fixation strut, $\mathrm{i}=$ implant, $\mathrm{sp}=$ free space; scale bar $=1000 \mu \mathrm{m}$ ). 


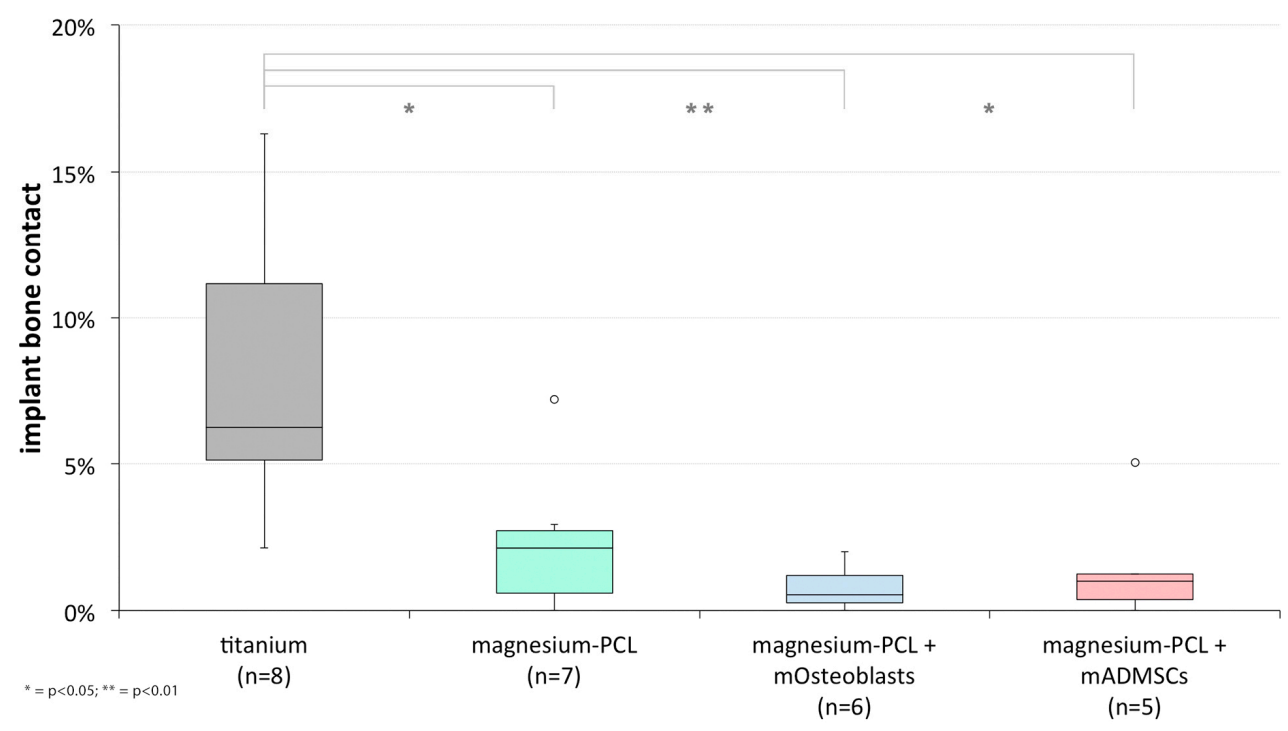

Figure 16. Implant bone contact (\%) of uncoated titanium implants, non-previtalised Mg-PCL implants and Mg-PCL implants previtalised with either mOsteoblasts or mADMSCs $\left({ }^{*}=p<0.05 ;{ }^{* *}=p<0.01\right.$; whiskers $=$ minimal and maximal values; horizontal line $=$ median; circles $=$ outliers $)$.

\section{Discussion}

The overall aim of this study was to evaluate the usage of PCL-coated and previtalised magnesium implants as an alternative to titanium for treating critically sized calvarial defects. While a balanced substitution rate of bone ingrowth and implant degradation were both desired and expected, the outcomes revealed an imbalance in favour of the latter. Namely, the analyses of the $\mu \mathrm{CT}$ scans showed a magnesium implant degradation of about $50 \%$ within 12 weeks, whereas there was only a significant bone formation within the first four weeks and only a slight increase during the remaining eight weeks of observation. The reason for the imbalance in implant bone substitution may lie either in an inadequate bone ingrowth or in a too rapid implant degradation. Judging from the outcomes of the bone volume $(\mu \mathrm{CT})$ and bone area (histomorphometry) measurements, both untreated and titanium implant-treated mice showed a similar amount of newly built bone tissue within the defect as magnesium-treated ones. Histomorphometrical analyses of the amount of osteoid also revealed no significant differences between the experimental groups. Therefore, within this study the porous implant geometry did not show osteoconductive effects although it is reported to do so in several studies $[46,47]$. Since the magnesium implants mostly lost their adhesion to the defect due to mechanical manipulation and gas formation caused by the degradation process, possible osteoconductive effects may not have been able to take place within the defect area. Thus, the impact of the scaffold geometry could only be observed by evaluating the titanium implants. While Taniguchi et al. [48] showed high bone ingrowth for titanium scaffolds with $600 \mu \mathrm{m}$ pore size, these effects could not be confirmed in our examinations. Rakhmatia et al. revealed that titanium meshes of $100 \mu \mathrm{m}$ thickness cause high bone ingrowth within calvarial defects in rats [49]. While in that case the mesh thickness was smaller than the host's calvaria, the implants used in our study were more than twice as thick as the murine skull bone. Therefore, an imbalance might have existed within the overall proportions between implant and host, resulting in the porous geometry not being accepted as such by the organism. The histomorphometrical analyses also showed an ingression of brain tissue within the lattice structure of the implants (Figure $4 \mathrm{~A}$, br), which might have hindered any other tissue, including bone, to infiltrate the implant pores. Since physiologically a consistent skull stabilises the intracranial pressure, as stated in the Monro-Kellie hypothesis [50], this phenomenon may be caused by the cerebral pressure itself. Therefore, it is possible that the pore spaces of the titanium implants had not been fully accessible since the day of surgery as the consistency of the skull was no longer existed. 
Although the implant geometry might not have positively influenced the bone ingrowth, the presence of an implant structure (titanium or magnesium) resulted in a significant increase in blood vessels within the osseous tissue on the defect treated skull side in comparison to non-implant-treated defects. As a minimal pore size of $400 \mu \mathrm{m}$ is reported to benefit the ingrowth of blood vessels [51], the implant geometry may have induced this phenomenon. Additionally, a previtalisation of Mg-PCL implants resulted in a significant increase in blood vessels compared to titanium implants and, in terms of previtalisation with mADMSCs, to Mg-PCL implants without previtalisation. This can be traced back to the production of proangiogenic factors of both osteoblasts and mesenchymal stem cells and therefore their ability to enhance the healing process as reported in various studies [52-55]. When comparing both the defect (and possibly implant) treated right and the untreated left skull side a significant increase from left to right could be detected for both control groups. Since both angiogenesis and vasculogenesis are essential for bone healing this reflects the higher presence of regeneration processes around the defect [56]. Surprisingly, within all magnesium-based groups no significant differences between both skull sides regarding intraosteal blood vessels could be observed, while each of them featured significantly higher amounts of blood vessels compared to both control groups on the left skull side. Also, both $\mu \mathrm{CT}$ and histomorphometrical analyses revealed a significantly higher amount of newly formed bone tissue on the left side for magnesium-treated mice in comparison to control group 1 (mice without implants). These alterations in vascularisation and bone formation might have been caused by the degradation process of the magnesium implants: Since all implants were fixated at the left skull side the mechanical forces of the moving implants might have been conducted along the elongated struts to the bony anchoring area. Since according to Wolff's law bone tissue structurally adapts to mechanical forces [57], the shifting magnesium scaffolds might have induced remodelling processes on the fixation site of the implants. Supporting this theory, Ikegame et al. discovered an osteoconductive effect of tensile stress within mouse calvarium organ cultures [58]. The correlation between the increase in bone volume/area and the magnesium corrosion would explain the absence of osseous remodeling on the left skull side within the titanium-treated group. The same applies to the significantly lesser amount of blood vessels. Against expectations, the overall bone formation within each experimental group was not sufficient enough to close the primarily set critical defect. However, it is remarkable that in all groups there was a significant increase in bone volume within the first 28 days, followed by only minimal growth during the subsequent 56 days of examination. The reason for this uncommon development may be found in the animals' age. Although mice are deemed to be classified as adult at the age of 12 weeks [59], Kilborn et al. stated that the murine growth plate closes at the age of about five months [60]. Since the $\mu \mathrm{CT}$ examinations revealed a significant increase in bone volume not just at the treated but also at the untreated skull side for control group 1, possible physiological bone transformations may have overlapped with the first phase of $\mu \mathrm{CT}$ observation. The changes in bone volume on the untreated side mainly resulted from an increase in the calvarium thickness, which affirms the hypothesis that the mice, although commonly considered as adult, had probably not completely finished their natural bone growth at the time of surgery. Focusing again on the substitution index, the magnesium implants seemed to degrade about five to six times faster than bone ingrowth took place. Judging from the resulting disconnection of the implants from the defect, the degradation process might carry more weight on the substitution index in comparison to the bone ingrowth. Although the free space around the implants is not just caused by the degradation process-since it also occurred while using non-degradable titanium implants-the latter seemed to enlarge it to a certain extent. Therefore, the main amount of this space may represent so-called gas pockets such as those observed in various studies using magnesium-based implants [42,44,61]. Zhang et al. also reported that the gas pockets were enveloped by connective tissue [61]. This phenomenon could partly be confirmed since there were also strands of connective tissue underneath the hybrid implants while in the other direction potential gas pockets were demarcated by physiological connective tissue of the skin. As stated by Wong et al., the surface-to-volume ratio of magnesium implants may affect the occurrence of gas pockets since a larger implant surface makes the implant more vulnerable 
to degradation processes. It was also stated that the gas release rate of highly corrosive implants might surpass the maximum absorption rate of the host's body, which then results in formation of gas pockets [32]. Due to its porous structure the surface-to-volume ratio of the implant geometry tested within our study was relatively high in comparison to the simple geometries used for long bone application. Therefore, it would also explain the absence of bone formation around the hybrid implants. In contrast, several studies reported proper bone formation in the presence of gas formation [62-64] but since these implants were always implanted in long bones the situation is not completely comparable to our study. Here, the main proportion of surrounding tissue was represented by skin and brain tissue so small changes in implant position may have disconnected it from the bony margins of the defect to an extent that may have made an interaction and therefore proper healing impossible. Although it is stated that PCL-coating enables a stable population of osteoblasts on coated magnesium implants in vitro [27], in our study it did not seem to contain the gas formation in dimensions that were needed for a proper fixation of the implants within the defect. As stated by Chen et al., the coating of pure magnesium with PCL leads to a specific interaction between the metal core and the polymer layer, resulting in a lowering of the corrosion resistance of the hybrid implant [29]. This may explain the rather fast degradation of the hybrid implants within our study compared to studies cited above which used alloyed magnesium as base material. Also, the mechanical manipulation of the implants during the previtalisation and implantation processes, although handled as gently as possible, may have caused scratches in the PCL-coating, resulting in an inconsistent polymer coating. Thus, created leaks may then have been passable for tissue fluid, resulting in a direct contact to the bare magnesium implant and therefore an accelerated degradation process. Several studies prove that PCL-coated magnesium implants show proper cytocompatibility to osteogenic cells in vitro [32,65] Although dissolved magnesium ions are stated to act osteoconductively by promoting osteoblast proliferation and therefore osteointegration [66] no comparable effect could be reported in our study. It is reported that the buffer capacity of surrounding fluids is crucial for the control of the effects of magnesium degradation on cell vitality and proliferation both in vitro and in vivo [67]. However, since within our study the hybrid implants were partly disconnected from surrounding tissue due to mechanical shifting and gas formation, the cells may have been exposed to the degradation process without any proper buffering system. Therefore, an uncontrolled change in $\mathrm{pH}$ value might have caused cell damage and death, which would explain the missing significant differences to non-previtalised samples in terms of osteointegration. When considering the increase in blood vessel formation within both previtalised hybrid implant groups the cells from the defect facing implant side may have also migrated to the surrounding natural bone structures locally, resulting in new formation of vascular tissue due to previously described mechanisms.

\section{Conclusions}

Regarding bone ingrowth inside the defect, the treatment with Mg-PCL implants resulted in neither significantly higher nor lower amounts of newly built bone tissue compared to the control groups. Previtalisation of those implants did not cause any significant changes in bone volume, area or amount of osteoid. Blood vessel formation around the defect was significantly higher within implant-treated mice, probably due to the positive effect of implant geometry and pore size, while a previtalisation of the Mg-PCL implants resulted in even significantly higher values. Magnesium implants degraded steadily but probably too fast, partially causing implants to lose their adhesion to the defect or to even be rejected by the animal. As a result, the percentage of implant bone contact was significantly lower compared to titanium and the substitution index for magnesium implants turned out to be five to six times higher than expected.

Overall, despite the insufficient degradation containment of the PCL-coating and the related effects thereof, magnesium-based implants proved to have no negative effects on bone regeneration. Furthermore, an additional previtalisation is favourable in terms of proper vascularisation. Although several refinements in corrosion resistance, fixation method and size wise implant host ratio are 
indicated for future examinations, this study still considers magnesium-based implants as being a promising alternative for treating critically sized calvarial defects.

Supplementary Materials: The following are available online at https:/ /figshare.com/s/e635c10c7571b0488cc9; Table S1: Median values and standard deviations for bone volume, implant volume, bone area, osteoid proportion and blood vessel observations. Figure S1: Exemplary $\mu \mathrm{CT}$ scan of a mouse treated with an uncoated titanium implant at day 0 (rostrocaudal view; i = implant with artefacts, s = skull); Figures S2-S29: Histological images of trichrome-masson-goldner stained thin sections of mice without implant (only defect; control group 1); Figures S30-S53: Histological images of trichrome-masson-goldner stained thin sections of mice treated with titanium implant (control group 2); Figures S54-S75: Histological images of trichrome-masson-goldner stained thin sections of mice treated with non-previtalised hybrid implant; Figures S76-S102: Histological images of trichrome-masson-goldner stained thin sections of mice treated with hybrid implant previtalised with murine osteoblasts; Figures S103-S124: Histological images of trichrome-masson-goldner stained thin sections of mice treated with hybrid implant previtalised with murine ADMSCs.

Acknowledgments: This study was approved by the Institutional Ethics Commission of the Lower Saxony Office for Consumer Protection and Food Safety (LAVES-Niedersächsisches Landesamt für Verbraucherschutz und Lebensmittelsicherheit (Germany); Project No. 33.12-42502-04-13/1355). The authors would like to thank Andreas Kampmann from the Hannover Medical School (MHH), Clinic for Cranio-Maxillo-Facial Surgery, Hannover, Germany for providing murine osteoblasts, Matthias Gieseke from the Laser Zentrum Hannover e.V. for providing the SLM- produced titanium and magnesium scaffolds and the German Research Foundation (Deutsche Forschungsgemeinschaft, DFG) for funding and supporting the project listed under support code No. 299/11-1.

Author Contributions: Ingo Nolte, Hugo Murua Escobar, Heinz Haferkamp, Nils-Claudius Gellrich, Hermann Seifert and Matthias Lüpke conceived and designed the experiments. Matthias Gieseke performed the metal implant manufacturing. Michael Teske performed the PCL- coating. Michael Grau, Christian Seiler, Claudia Windhövel, Laura Roland and Julia Matena performed the experiments. Michael Grau and Christian Seiler analysed the data and wrote the paper.

Conflicts of Interest: The authors declare no conflicts of interest. Our financial sponsors had no role in the design of the study neither in the collection, analyses, or interpretation of data nor in the writing of the manuscript and the decision to publish the results.

\section{References}

1. Carano, R.A.D.; Filvaroff, E.H. Angiogenesis and bone repair. Drug Discov. Today 2003, 8, 980-989. [CrossRef]

2. Gellrich, N.C.; Held, U.; Schoen, R.; Pailing, T.; Schramm, A.; Bormann, K.H. Alveolar zygomatic buttress: A new donor site for limited preimplant augmentation procedures. J. Oral Maxillofac. Surg. 2007, 65, 275-280. [CrossRef] [PubMed]

3. Schmitz, J.P.; Hollinger, J.O. The Critical Size Defect as an Experimental-Model for Craniomandibulofacial Nonunions. Clin. Orthop. Relat. Res. 1986, 205, 299-308. [CrossRef]

4. Moshaverinia, A.; Chen, C.; Xu, X.; Akiyama, K.; Ansari, S.; Zadeh, H.; Shi, S. Bone Regeneration Potential of Stem Cells Derived from Periodontal Ligament or Gingival Tissue Sources Encapsulated in RGD-Modified Alginate Scaffold. Tissue Eng. Part A 2014, 20, 611-621. [CrossRef] [PubMed]

5. Cooper, G.M.; Mooney, M.P.; Gosain, A.K.; Campbell, P.G.; Losee, J.E.; Huard, J. Testing the "critical-size" in calvarial bone defects: Revisiting the concept of a critical-sized defect (CSD). Plast. Reconstr. Surg. 2010, 125, 1685-1692. [CrossRef] [PubMed]

6. Gosain, A.K.; Song, L.S.; Yu, P.R.; Mehrara, B.J.; Maeda, C.Y.; Gold, L.I.; Longaker, M.T. Osteogenesis in cranial defects: Reassessment of the concept of critical size and the expression of TGF-beta isoforms. Plast. Reconstr. Surg. 2000, 106, 360-371. [CrossRef] [PubMed]

7. Aalami, O.O.; Nacamuli, R.P.; Lenton, K.A.; Cowan, C.M.; Fang, T.D.; Fong, K.D.; Shi, Y.Y.; Song, H.M.; Sahar, D.E.; Longaker, M.T. Applications of a Mouse Model of Calvarial Healing: Differences in Regenerative Abilities of Juveniles and Adults. Plast. Reconstr. Surg. 2004, 114, 713-720. [CrossRef] [PubMed]

8. Cowan, C.M.; Shi, Y.Y.; Aalami, O.O.; Chou, Y.F.; Mari, C.; Thomas, R.; Quarto, N.; Contag, C.H.; Wu, B.; Longaker, M.T. Adipose-derived adult stromal cells heal critical-size mouse calvarial defects. Nat. Biotechnol. 2004, 22, 560-567. [CrossRef] [PubMed]

9. Wu, X.; Downes, S.; Watts, D.C. Evaluation of critical size defects of mouse calvarial bone: An organ culture study. Microsc. Res. Tech. 2010, 73, 540-547. [CrossRef] [PubMed]

10. Geiger, M.; Li, R.H.; Friess, W. Collagen sponges for bone regeneration with rhBMP-2. Adv. Drug Deliv. Rev. 2003, 55, 1613-1629. [CrossRef] [PubMed] 
11. Goulet, J.A.; Senunas, L.E.; DeSilva, G.L.; Greenfield, M.L.V.H. Autogenous iliac crest bone graft-Complications and functional assessment. Clin. Orthop. Relat. Res. 1997, 339, 76-81. [CrossRef]

12. Silber, J.S.; Anderson, D.G.; Daffner, S.D.; Brislin, B.T.; Leland, J.M.; Hilibrand, A.S.; Vaccaro, A.R.; Albert, T.J. Donor site morbidity after anterior iliac crest bone harvest for single-level anterior cervical discectomy and fusion. Spine 2003, 28, 134-139. [CrossRef] [PubMed]

13. Sasso, R.C.; LeHuec, J.C.; Shaffrey, C.; Grp, S.I.R. Iliac crest bone graft donor site pain after anterior lumbar interbody fusion-A prospective patient satisfaction outcome assessment. J. Spinal Disord. Tech. 2005, 18, 77-81. [CrossRef]

14. Li, J.P.; Li, S.H.; Van Blitterswijk, C.A.; De Groot, K. Cancellous bone from porous Ti6Al4V by multiple coating technique. J. Mater. Sci. Mater. M 2006, 17, 179-185. [CrossRef] [PubMed]

15. Zhu, K.; Li, C.F.; Zhu, Z.G.; Liu, C.S. Measurement of the dynamic Young's modulus of porous titanium and Ti6Al4V. J. Mater. Sci. 2007, 42, 7348-7353. [CrossRef]

16. Huiskes, R.; Weinans, H.; Vanrietbergen, B. The Relationship between Stress Shielding and Bone-Resorption around Total Hip Stems and the Effects of Flexible Materials. Clin. Orthop. Relat. Res. 1992, 274, 124-134. [CrossRef]

17. Charyeva, O.; Thormann, U.; Lips, K.S.; Heimann, L.; Sommer, U.; Szalay, G.; Alt, V.; Hort, N.; Schnettler, R.; Rauschmann, M.; et al. Histological Comparison of New Biodegradable Magnesium-Based Implants for Maxillofacial Applications. J. Maxillofac. Oral Surg. 2015, 14, 637-645. [CrossRef] [PubMed]

18. Janning, C.; Willbold, E.; Vogt, C.; Nellesen, J.; Meyer-Lindenberg, A.; Windhagen, H.; Thorey, F.; Witte, F. Magnesium hydroxide temporarily enhancing osteoblast activity and decreasing the osteoclast number in peri-implant bone remodelling. Acta Biomater. 2010, 6, 1861-1868. [CrossRef] [PubMed]

19. Waizy, H.; Seitz, J.M.; Reifenrath, J.; Weizbauer, A.; Bach, F.W.; Meyer-Lindenberg, A.; Denkena, B.; Windhagen, H. Biodegradable magnesium implants for orthopedic applications. J. Mater. Sci. 2013, 48, 39-50. [CrossRef]

20. Fischerauer, S.F.; Kraus, T.; Wu, X.; Tangl, S.; Sorantin, E.; Hanzi, A.C.; Loffler, J.F.; Uggowitzer, P.J.; Weinberg, A.M. In vivo degradation performance of micro-arc-oxidized magnesium implants: A micro-CT study in rats. Acta Biomater. 2013, 9, 5411-5420. [CrossRef] [PubMed]

21. Kraus, T.; Fischerauer, S.F.; Hanzi, A.C.; Uggowitzer, P.J.; Loffler, J.F.; Weinberg, A.M. Magnesium alloys for temporary implants in osteosynthesis: In vivo studies of their degradation and interaction with bone. Acta Biomater. 2012, 8, 1230-1238. [CrossRef] [PubMed]

22. Agarwal, S.; Curtin, J.; Duffy, B.; Jaiswal, S. Biodegradable magnesium alloys for orthopaedic applications: A review on corrosion, biocompatibility and surface modifications. Mater. Sci. Eng. C Mater. Biol. Appl. 2016, 68, 948-963. [CrossRef] [PubMed]

23. Qu, S.; Xia, J.; Yan, J.; Wu, H.; Yi, Y.; Zhang, X.; Zhang, S.; Zhao, C.; Chen, Y. In vivo and in vitro assessment of the biocompatibility and degradation of high-purity $\mathrm{Mg}$ anastomotic staples. J. Biomater. Appl. 2017, 31, 1203-1214. [CrossRef] [PubMed]

24. Huehnerschulte, T.A.; Reifenrath, J.; von Rechenberg, B.; Dziuba, D.; Seitz, J.M.; Bormann, D.; Windhagen, H.; Meyer-Lindenberg, A. In vivo assessment of the host reactions to the biodegradation of the two novel magnesium alloys ZEK100 and AX30 in an animal model. Biomed. Eng. Online 2012, 11. [CrossRef] [PubMed]

25. Song, G.L.; Atrens, A. Corrosion mechanisms of magnesium alloys. Adv. Eng. Mater. 1999, 1, 11-33. [CrossRef]

26. Shadanbaz, S.; Walker, J.; Woodfield, T.B.; Staiger, M.P.; Dias, G.J. Monetite and brushite coated magnesium: In vivo and in vitro models for degradation analysis. J. Mater. Sci. Mater. Med. 2014, 25, 173-183. [CrossRef] [PubMed]

27. Matena, J.; Petersen, S.; Gieseke, M.; Teske, M.; Beyerbach, M.; Kampmann, A.; Escobar, H.M.; Gellrich, N.C.; Haferkamp, H.; Nolte, I. Comparison of Selective Laser Melted Titanium and Magnesium Implants Coated with PCL. Int. J. Mol. Sci. 2015, 16, 13287-13301. [CrossRef] [PubMed]

28. Woodruff, M.A.; Hutmacher, D.W. The return of a forgotten polymer-Polycaprolactone in the 21st century. Prog. Polym. Sci. 2010, 35, 1217-1256. [CrossRef]

29. Chen, Y.; Song, Y.; Zhang, S.X.; Li, J.N.; Zhao, C.L.; Zhang, X.N. Interaction between a high purity magnesium surface and PCL and PLA coatings during dynamic degradation. Biomed. Mater. 2011, 6. [CrossRef] [PubMed]

30. Xu, L.P.; Yamamoto, A. Characteristics and cytocompatibility of biodegradable polymer film on magnesium by spin coating. Colloid Surf. B 2012, 93, 67-74. [CrossRef] [PubMed] 
31. Cipitria, A.; Reichert, J.C.; Epari, D.R.; Saifzadeh, S.; Berner, A.; Schell, H.; Mehta, M.; Schuetz, M.A.; Duda, G.N.; Hutmacher, D.W. Polycaprolactone scaffold and reduced rhBMP-7 dose for the regeneration of critical-sized defects in sheep tibiae. Biomaterials 2013, 34, 9960-9968. [CrossRef] [PubMed]

32. Wong, H.M.; Yeung, K.W.; Lam, K.O.; Tam, V.; Chu, P.K.; Luk, K.D.; Cheung, K.M. A biodegradable polymer-based coating to control the performance of magnesium alloy orthopaedic implants. Biomaterials 2010, 31, 2084-2096. [CrossRef] [PubMed]

33. Jo, J.H.; Li, Y.; Kim, S.M.; Kim, H.E.; Kob, Y.H. Hydroxyapatite/poly(epsilon-caprolactone) double coating on magnesium for enhanced corrosion resistance and coating flexibility. J. Biomater. Appl. 2013, 28, 617-625. [CrossRef] [PubMed]

34. Loh, Q.L.; Choong, C. Three-Dimensional Scaffolds for Tissue Engineering Applications: Role of Porosity and Pore Size. Tissue Eng. Part B Rev. 2013, 19, 485-502. [CrossRef] [PubMed]

35. Carvalho, P.P.; Leonor, I.B.; Smith, B.J.; Dias, I.R.; Reis, R.L.; Gimble, J.M.; Gomes, M.E. Undifferentiated Human Adipose-derived Stromal/Stem Cells loaded onto Wet-Spun Starch-polycaprolactone Scaffolds Enhance Bone Regeneration: Nude Mice Calvarial Defect in vivo Study. J. Biomed. Mater. Res. A 2015, 102, 3102-3111. [CrossRef] [PubMed]

36. Huang, Z.; Bryan, J.; Horton, W.; Sandell, L. Chondrogenic, osteogenic and adipogenic differentiation of pluripotent adipose-derived stem cells from type II collagen promoter-driven GFP mice. J. Bone Miner. Res. 2004, 19, 215.

37. Levi, B.; James, A.W.; Nelson, E.R.; Vistnes, D.; Wu, B.; Lee, M.; Gupta, A.; Longaker, M.T. Human Adipose Derived Stromal Cells Heal Critical Size Mouse Calvarial Defects. PLoS ONE 2010, 5, e11177. [CrossRef] [PubMed]

38. Zuk, P.A.; Zhu, M.; Ashjian, P.; De Ugarte, D.A.; Huang, J.I.; Mizuno, H.; Alfonso, Z.C.; Fraser, J.K.; Benhaim, P.; Hedrick, M.H. Human adipose tissue is a source of multipotent stem cells. Mol. Biol. Cell 2002, 13, 4279-4295. [CrossRef] [PubMed]

39. Hicok, K.C.; Du Laney, T.V.; Zhou, Y.S.; Halvorsen, Y.D.C.; Hitt, D.C.; Cooper, L.F.; Gimble, J.M. Human adipose-derived adult stem cells produce osteoid in vivo. Tissue Eng. 2004, 10, 371-380. [CrossRef] [PubMed]

40. Gimble, J.M.; Guilak, F. Adipose-derived adult stem cells: Isolation, characterization, and differentiation potential. Cytotherapy 2003, 5, 362-369. [CrossRef] [PubMed]

41. Abdal-Hay, A.; Amna, T.; Lim, J.K. Biocorrosion and osteoconductivity of PCL/nHAp composite porous film-based coating of magnesium alloy. Solid State Sci. 2013, 18, 131-140. [CrossRef]

42. Song, G. Control of biodegradation of biocompatible magnesium alloys. Corros. Sci. 2007, 49, $1696-1701$. [CrossRef]

43. Li, L.; Zhang, M.; Li, Y.; Zhao, J.; Qin, L.; Lai, Y. Corrosion and biocompatibility improvement of magnesium-based alloys as bone implant materials: A review. Regen. Biomater. 2017, 4, 129-137. [CrossRef]

44. González, S.; Pellicer, E.; Suriñach, S.; Baró, M.D.; Sort, J. Biodegradation and Mechanical Integrity of Magnesium and Magnesium Alloys Suitable for Implants. In Biodegradation-Engineering and Technology; InTech: Rijeka, Croatia, 2013; Chapter 12.

45. Gieseke, M. Entwicklung des Selektiven Laserschmelzens von Magnesium und Magnesiumlegierungen zur Herstellung von Individuellen und Bioresorbierbaren Implantaten, 1st ed.; PZH Verlag: Hannover, Germany, 2015; pp. 1-193. ISBN 978-3-95900-046-8.

46. De Wild, M.; Schumacher, R.; Mayer, K.; Schkommodau, E.; Thoma, D.; Bredell, M.; Kruse Gujer, A.; Grätz, K.W.; Weber, F.E. Bone regeneration by the osteoconductivity of porous titanium implants manufactured by selective laser melting: A histological and micro computed tomography study in the rabbit. Tissue Eng. Part A 2013, 19, 2645-2654. [CrossRef] [PubMed]

47. Chang, B.S.; Lee, C.K.; Hong, K.S.; Youn, H.J.; Ryu, H.S.; Chung, S.S.; Park, K.W. Osteoconduction at porous hydroxyapatite with various pore configurations. Biomaterials 2000, 21, 1291-1298. [CrossRef]

48. Taniguchi, N.; Fujibayashi, S.; Takemoto, M.; Sasaki, K.; Otsuki, B.; Nakamura, T.; Matsushita, T.; Kokubo, T.; Matsuda, S. Effect of pore size on bone ingrowth into porous titanium implants fabricated by additive manufacturing: An in vivo experiment. Mater. Sci. Eng. C Mater. Biol. Appl. 2016, 59, 690-701. [CrossRef] [PubMed]

49. Rakhmatia, Y.D.; Ayukawa, Y.; Furuhashi, A.; Koyano, K. Microcomputed tomographic and histomorphometric analyses of novel titanium mesh membranes for guided bone regeneration: A study in rat calvarial defects. Int. J. Oral Maxillofac. Implants 2014, 29, 826-835. [CrossRef] [PubMed] 
50. Mokri, B. The Monro-Kellie hypothesis: Applications in CSF volume depletion. Neurology 2001, 56, 1746-1748. [CrossRef] [PubMed]

51. Feng, B.; Jinkang, Z.; Zhen, W.; Jianxi, L.; Jiang, C.; Jian, L.; Guolin, M.; Xin, D. The effect of pore size on tissue ingrowth and neovascularisation in porous bioceramics of controlled architecture in vivo. Biomed. Mater. 2011, 6. [CrossRef] [PubMed]

52. Deckers, M.M.; van Bezooijen, R.L.; van der Horst, G.; Hoogendam, J.; van Der Bent, C.; Papapoulos, S.E.; Löwik, C.W. Bone morphogenetic proteins stimulate angiogenesis through osteoblast-derived vascular endothelial growth factor A. Endocrinology 2002, 143, 1545-1553. [CrossRef] [PubMed]

53. Huang, B.; Wang, W.; Li, Q.; Wang, Z.; Yan, B.; Zhang, Z.; Wang, L.; Huang, M.; Jia, C.; Lu, J.; et al. Osteoblasts secrete $\mathrm{Cxcl} 9$ to regulate angiogenesis in bone. Nat. Commun. 2016, 7. [CrossRef] [PubMed]

54. Chen, L.; Tredget, E.E.; Wu, P.Y.; Wu, Y. Paracrine factors of mesenchymal stem cells recruit macrophages and endothelial lineage cells and enhance wound healing. PLOS ONE 2008, 3, e1886. [CrossRef] [PubMed]

55. Melchiorri, A.J.; Nguyen, B.N.; Fisher, J.P. Mesenchymal Stem Cells: Roles and Relationships in Vascularisation. Tissue Eng. Part B Rev. 2014, 20, 218-228. [CrossRef] [PubMed]

56. Hankenson, K.D.; Dishowitz, M.; Gray, C.; Schenker, M. Angiogenesis in Bone Regeneration. Injury 2011, 42, 556-561. [CrossRef] [PubMed]

57. Frost, H.M. Wolff's Law and bone's structural adaptations to mechanical usage: An overview for clinicians. Angle Orthod. 1994, 64, 175-188. [PubMed]

58. Ikegame, M.; Ishibashi, O.; Yoshizawa, T.; Shimomura, J.; Komori, T.; Ozawa, H.; Kawashima, H. Tensile stress induces bone morphogenetic protein 4 in preosteoblastic and fibroblastic cells, which later differentiate into osteoblasts leading to osteogenesis in the mouse calvariae in organ culture. J. Bone Miner. Res. 2001, 16, 24-32. [CrossRef] [PubMed]

59. Dutta, S.; Sengupta, P. Men and mice: Relating their ages. Life Sci. 2016, 152, 244-248. [CrossRef] [PubMed]

60. Kilborn, S.H.; Trudel, G.; Uhthoff, H. Review of growth plate closure compared with age at sexual maturity and lifespan in laboratory animals. Contemp. Top. Lab. Anim. Sci. 2002, 41, 21-26. [PubMed]

61. Zhang, S.; Zhang, X.; Zhao, C.; Li, J.; Song, Y.; Xie, C.; Tao, H.; Zhang, Y.; He, Y.; Jiang, Y.; et al. Research on an Mg-Zn alloy as a degradable biomaterial. Acta Biomater. 2010, 6, 626-640. [CrossRef] [PubMed]

62. Amerstorfer, F.; Fischerauer, S.F.; Fischer, L.; Eichler, J.; Draxler, J.; Zitek, A.; Meischel, M.; Martinelli, E.; Kraus, T.; Hann, S.; et al. Long-term/react-text in vivo react-text: 84 degradation behavior and near-implant distribution of resorbed elements for magnesium alloys WZ21 and ZX50. Acta Biomater. 2016, 42, 440-450. [CrossRef] [PubMed]

63. Wang, J.; Jiang, H.; Bi, Y.; Sun, J.; Chen, M.; Liu, D. Effects of gas produced by degradation of Mg-Zn-Zr Alloy on cancellous bone tissue. Mater. Sci. Eng. C Mater. Biol. Appl. 2015, 55, 556-561. [CrossRef] [PubMed]

64. Witte, F.; Kaese, V.; Haferkamp, H.; Switzer, E.; Meyer-Lindenberg, A.; Wirth, C.J.; Windhagen, H. In vivo corrosion of four magnesium alloys and the associated bone response. Biomaterials 2005, 26, 3557-3563. [CrossRef] [PubMed]

65. Chuenjitkuntaworn, B.; Osathanon, T.; Nowwarote, N.; Supaphol, P.; Pavasant, P. The efficacy of polycaprolactone/hydroxyapatite scaffold in combination with mesenchymal stem cells for bone tissue engineering. J. Biomed. Mater. Res. A 2016, 104, 264-271. [CrossRef] [PubMed]

66. Gao, J.-C.; Qiao, L.-Y.; Xin, R.-L. Effect of $\mathrm{Mg}^{2+}$ concentration on biocompatibility of pure magnesium. Front. Mater. Sci. China 2010, 4, 126-131. [CrossRef]

67. Zhen, Z.; Liu, X.; Huang, T.; Xi, T.F.; Zheng, Y. Hemolysis and cytotoxicity mechanisms of biodegradable magnesium and its alloys. Mater. Sci. Eng. C 2015, 46, 202-206. [CrossRef] [PubMed]

(C) 2017 by the authors. Licensee MDPI, Basel, Switzerland. This article is an open access article distributed under the terms and conditions of the Creative Commons Attribution (CC BY) license (http://creativecommons.org/licenses/by/4.0/). 